\title{
HEALTH PLANNING FOR DEREGULATION: IMPLEMENTING THE 1979 AMENDMENTS*
}

\author{
Clark C. Havigihlosit ${ }^{\dagger}$
}

Its time was slow in coming, but the idea of deregulation of the health services industry must now be taken seriously. Although the option of letting market forces allocate resources to and within the health care industry has had academic support in the health policy debate for at least ten years, ${ }^{\prime}$ until very recently in policy circles there was a near consensus that the fundamental choice to rely primarily on regulation had already been made. ${ }^{2}$ The only issues recognized on the policy agenda involved how to make existing regulatory institutions work better and how best to extend regulation's grip. But the year 1979 changed all that, as the 96th Congress sharply reversed the trend toward tighter regulatory controls. Not only did Congress reject the Carter Administration's heavy-handed proposal for hospital cost containment, ${ }^{3}$ but it also significantly reduced the jurisdiction and revised the mandate of state and local health planning and regulatory agencies under the National Health Planning and Resources Development Act of 1974. ${ }^{4}$ Competition and consumer preferences were thus reintroduced as viable candidates for a major role in disciplining the health care sector.

This article concerns the implementation of Public Law 96-79, the National Health Planning and Resources Development Amendments of 1979..$^{5}$ The thesis is that these amendments, properly understood, make substantial deregulation of the health services industry a realistic future possibility. After a brief statement of the nature and purposes of health planning and related regulation, the article sketches the recent policy developments that led Congress in 1979 to give the original health planning law a new, deregulatory thrust. After a short exposition of the

\footnotetext{
* Copyright 1981 by Duke University. Major portions of this paper are adapted from work supported, though not necessarily endorsed, by the Federal Trade Commission and the National Center for Health Services Research, Department of Health and Human Services (Grant No. HS 01539). The author is completing a book that will incorporate some of the material herein.

$\dagger$ Professor of Law, Duke Lniversity.

1. See, e.g., Ellwood, Anderson et al., Health Maintenance Strategr. 9 Mr.1. C.Akf 291 (1971); Feldstein. A New Approach to National Health Insurance, PtB. INIfresi 93 (Spring 1971); Havighurst, Henlth Maintenance Organizations and the Market for Health Services, 35 Law \& Cowrus. Pkos. 716 (1970): Newhouse \& Taylor, How Shall We Pay for Hospital Care? P('s. INirkrsl 78 (Spring 1971).

2. Cf. Weiner, Governmental Regulation of Health Care: A Respomse to Some Criticisms Voiced by Proponents of a "Free Market," 4 AM. J. L. \& MED. 15 (1978): Wing \& Craige, Health Care Regulation: Dilemma of a Partially Developed Public Policy, 57 N.C. L. RE.. 1165, 1167 (1979).

3. Debate on H.R. 2626, 96th Cong. Ist Sess., 125 CoNc. Rrc. H10.809 (daily ed. Nov. 15, 1979).

4. National Health Planning and Resources Development Amendments of 1979. Pub. L. No. 96-79, 93 Stat. 592 [amending the National Health Planning and Resources Development Act of 1974 (Titles XV and XVI of the Public Health Service Act), Pub. L. No. 93-64l. 88 Stat. 2225: 42 U.S.C. $\$ \$ 300 \mathrm{k} e t$ seq. (1976 \& Supp. II 1978)] [Hereinafter Pub. L. No. 96-79 will be cited as Planning Amendments of $1979]$.

5. Id.
} 
amendments' reintroduction of competition as a desideratum in health sector regulation, the article examines, in some depth, the ways in which health system planner-regulators must now think about the industry they oversee and must address their regulatory and nonregulatory responsibilities. Their new assignment under the 1979 amendments is, first, to appraise the market's ability to function in allocating particular health services and resources and, second, to "give priority" to the idea of allowing market forces to operate with respect to those specific services that can reasonably be expected to respond to consumer preferences, including cost concerns. Whether the health care system's planning and regulatory components will carry out this new mandate in the right spirit and whether regulation will be gradually displaced by market forces remains to be seen, of course, but there should be no question that Congress has declared a rather clear preference in these regards.

Without appreciable experience in analyzing the potential value of competition and private incentives as controls on system development, the health care industry's planner-regulators are necessarily approaching their new responsibilities with great uncertainty and few tools. This article is a tentative attempt ${ }^{6}$ to get them thinking in a balanced way about some highly complex matters and to encourage them to take an active part in what might turn out to be a particularly exciting and promising deregulatory endeavor.

Ebb and Flow in the Regulation-Competition Debate

A. The Heyday of Health Planning and Regulation

Health planning was coupled with regulation in the 1960s and the early 1970 s in an effort to deal with what appeared to be inappropriate proliferation of hospital and other institutional health services. ${ }^{7}$ Previously, planning agencies had developed at the local level to serve a variety of different functions, including the establishment of priorities in the use of philanthropic and governmental funds and the allocation of service and geographic markets among hospitals anxious to minimize competition. ${ }^{8}$ In due course, however, the dominant concerns of health planning became less and less the allocation of limited resources to their best uses and the curbing of competition both for those limited funds and for price-sensitive customers. Increasingly, with the growth of health insurance and public financing, the perceived challenge was how to limit the system's exploitation of open-ended financing sources and how to curb emerging nonprice competition, which was

6. A fuller version of the analysis undertaken by this article will appear in C. HAvichLRST, Competition in a Regulated Health Care System (forthcoming).

7. For overviews of health planning and certificate-of-need regulation, see Regulating HEAlth Facilities Construction: Proceedings of a Conference on Health Planning, Certificates of Need, and Market EnTRY (C. Havighurst ed. 1974); Havighurst, Regulation of Health Facilities and Services by "Certificate of Need," 59 VA. L. REv. 1143 (1973).

8. See Gottlieb, A Brief History of Health Planning in the United States, in Recilating; Health Fachitities Construction, supra note 7. 
driving the system to incur unjustified costs. The health planning system offered itself as a vehicle suitable for rationalizing the health system's development in these respects and gained increasing federal support throughout the $1960 \mathrm{~s}$. Decisions by planning agencies were gradually seen to require "teeth" to make them effective in the face of voluntary noncompliance, and state "certificate-of-need" laws began to appear, giving state authorities the regulatory power to act, usually with local planners' advice, to prevent undesired growth. ${ }^{9}$

Early federal support for the health planning enterprise and other localized health programs was reexamined in the early 1970s. The result of this reexamination was the National Health Planning and Resources Development Act of 1974. That law restructured the planning effort by establishing, largely at federal expense, a system of 200-plus local health systems agencies (HSAs) that were to perform a variety of functions aimed at defining community needs and seeing that they were met. The law required that every state adopt in due course a certificate-ofneed law empowering the local planners and state regulators, acting cooperatively, to prohibit unapproved proliferation of facilities and institutional services. The law's thrust was clearly toward centralizing at the local level the significant decisions on capital investments and service offerings. The Senate committee report on the new law, in a much quoted statement which seems to have been intended as a coup de grace aimed at advocates of competition in health services, declared the committee's view that "the health care industry does not respond to classic marketplace forces." 10

The central-planning orientation was clearly dominant in those days. Even the Health Maintenance Organization Act of 1973 (HMO), ${ }^{11}$ which encouraged the development of an innovative and highly procompetitive form of health care delivery, was adopted without appreciable reference to the possible value of competition. Availability of the HMO alternative was encouraged, through subsidies and otherwise, to promote pluralism-that is, choice among different delivery modes-than to stimulate economic competition among health care prepayment plans at one level and among health care providers at another. ${ }^{12}$ Again the Congressional committees and their staffs seemed determined to write legislative history that gave no comfort to competition advocates. ${ }^{13}$

9. For a summary of these developments, see Havighurst, Regulation of Health Facilities and Services by "Certificate of Need," supra note 7, at 1148-55.

10. S. Rf.P. No. 1285, 93d Cong., 2d Sess., reprinted in [1974] U.S. Codr CoNci. \& Av. News 7878.

11. Health Maintenance Organization Act of 1973 (as amended), 42 U.S.C. $\$ \$ 300$ e et seq. (1976 \& Supp. II 1978).

12. Havighurst \& Bovbjerg, Professional Standards Review Organizations and Health Maintenance Organizations: Are They Compatible? 1975 UTAH L. REv. 381, 383-87. For example, under the HMO Act's "dual choice" requirement, an employer with more than twenty-five employees and a health benefits plan must offer those employees the option of joining a federally qualified HMO. If both a group practice model HMO and an individual practice association (IPA) model HMO are available, the employer must offer an HMO of each type. 42 U.S.C. $\$ 300$ e-9 (1976 \& Supp. II 1978). Thus, a second group practice HMO or a second IPA-HMO has no right to be offered; and HMOs not meeting all of the demanding federal requirements are no better off than they would be without the law. Yet meaningful competition cannot be assured by the existence of two, or even three, competitors. See Enthoven, Competition of Alternative Health Care Delivery Systems in U.S. Federal Trade. Comm'v, Competition in the Health Care Sector: Past, Presext, and Fltire 322,337-44 (W. Greenberged. 1978).

13. See National Academy of Sciences, Institute of Medicine, Health Mantenance Orcan- 
The dominant item on the health policy agenda throughout most of the $1970 \mathrm{~s}$ was the need to create an infrastructure of cost-containment regulation that would permit the expansion of federally run or federally mandated financing programs and realization of the long-deferred promise of "national health insurance." In this context, reinvigoration of the private market for health insurance (or other prepayment plans) and health services was neglected as a policy objective. Indeed, to many governmental observers and advocates of governmental solutions, the private sector's failure was perceived more as an opportunity to be exploited than as a problem to be solved. Few observers in Washington in the mid-1970s would have acknowledged even a faint possibility that government's regulatory power over health services would do anything but increase.

\section{B. The Pendulum Swings Back}

Several developments helped to trigger the policy re-evaluation that culminated in the significant policy shift that began to take tangible form in 1979. First, health care costs continued to escalate throughout the 1970s. ${ }^{14}$ Had the rate of increase of health costs in an inflationary economy simply levelled off and become a stable share of both the gross national product and federal expenditures, political concern over the level of spending and the system's fundamental soundness would have evaporated-even if the system was in fact absorbing vast resources that could have been put to better uses elsewhere. In other words, even a serious misallocation of resources would not, in itself, have been enough to sustain Congressional attention to the industry's basic problems. Regulation, in order to secure its victory in the policy debate, would have had to succeed only in permanently levelling off the relative rate of growth, at any point attained during the entire period. If it had achieved that seemingly easy objective, regulation would never have been called to account for any departure, no matter how great, from the social optimum, either in total expenditures or in the way health funds are in fact employed in the system.

Besides regulation's failure to contain costs at the macro level, its failures at the micro level also contributed to reopening the health policy debate. Not only did several studies of health sector regulation in general and of certificate-of-need regulation in particular indicate substantial ineffectiveness, ${ }^{15}$ but it was also increasingly

IZATIONS: TOWARd A Fair MARKet TEST 83-98 (1974); Hearings on Competition in the Health Services Market Before the Subcomm. on Antitrust and Monopoly of the Senate Comm. on the Judiciary, 93d Cong., 2d Sess., pt. 2, at 1078-82 (1974) (Statement of Clark C. Havighurst); Starr, The Undelivered Health System, Pub. INTEREST 66 (Winter 1976).

14. For relevant data on past increases in health care expenditures and projections of future increases, see Freeland, Calat \& Schendler, Projections of National Health Expenditures, 1980, 1985, and 1990, Health Care Financing Rev. 1 (Winter 1980).

15. See, e.g., Salkever \& Bice, Hospital Certificite-of-Nf.ji (ontrol.s (1979): Sloan \& Steinwald, Effects of Regulation on Hospital Costs and Use. 23 J. L. \& E(0). 81 (1980); (innsburg. Impact of the Economic Stabilization Program on Hospitals, in Hospital. Cost CoNTalNMext 293 (M. Zubkoff, I. Raskin, \& R. Hanft eds. 1978); Policy Analysis, Inc., Evaluation of the Effects of Certificate of Need Programs (forthcoming). But see Sloan, Regulation and the Rising Cost of Hospital Care (1980) (unpublished paper suggesting that certificate of need programs have no effect, but well-established prospective reimbursement programs do lower hospital costs). 
perceived that it might be unrealistic to expect regulation, at least as currently constituted, to perform the cost-containment job. ${ }^{16}$ For one thing, the incentives for effective cost containment by local agencies were weak because, where the benefits of added spending would be enjoyed by local providers and patients, much of the savings from foregoing those benefits would accrue in the first instance to government programs and health insurers and ultimately to taxpayers and premium payers located outside the area. Moreover, HSAs and certificate-of-need agencies were not comfortable in their role as naysayers, finding it hard to deny arguable health benefits to patients and to contest providers' claims concerning the contributions that new investments would make to better "quality" and to meeting patients' "needs." It is easy to appreciate why politically exposed regulators might be unable to address quality/cost trade-offs when the analysis requires putting at least implicit finite values on the health status and life chances of citizens.

Despite these disincentives to impose stringent limits, certificate-of-need programs might still have been expected to control the growth of the supply of excess hospital beds since, almost by definition, unused or duplicative facilities have no apparent implications for individuals' health. According to a prominent study by Salkever and Bice, the bed complement was indeed controlled somewhat by certificate-of-need controls. ${ }^{17}$ But that study also indicated that certification-of-need had no significant effect on aggregate hospital investment, since capital investment per bed rose to offset the savings from preventing the creation of new beds. ${ }^{18} \mathrm{~A}$ more recent study by Policy Analysis, Inc., covering a longer time period and testing the possibility that regulatory programs with particular characteristics might have greater success, has also found no important contribution to overall cost containment by certificate-of-need programs. ${ }^{19}$ Other forms of regulation have also not been shown to make appreciable differences in overall costs. ${ }^{20}$ While it cannot yet be said that regulation is totally discredited, Congress has been unable to conclude that the programs it has put in place are anywhere near being sufficient unto the need.

One particular confession of regulatory failure contributed directly to Congress' apparent reexamination in 1979 of its health policy premises. The Carter Administration's hospital cost containment bill, first introduced in $1977,{ }^{21}$ confronted Congress with a new type of regulatory control that, while promising somewhat greater effectiveness in cost containment, carried with it implications that were more troublesome than those of earlier regulatory programs. In seeking to impose a flat percentage limit on the growth of each hospital's revenue, the bill took an

16. Cf. Havighurst, Health Care Cost-Containment Regulation: Prospects and an Alternative, 3 Ax. J. L. \& MED. 309 (1979).

17. Salkever \& Bice, supra note 15 , at 51.

18. Id.

19. Policy Analysis, Inc., supra note 15.

20. Sloan \& Steinwald, supra note 15 (measuring the impact of controls on expansion of facilities and services, controls on allowable revenue and/or cost increases, and controls on utilization of hospital services). But see Sloan, supra note 15

21. S. 1391, H.R. 6575, 95th Cong., Ist Sess. (1977): S. 570. H.R. 2626, 96th Cong., I st Sess. (1979). 
arbitrary approach to cost containment. Although the bill was amended in an attempt to mute that particular criticism by vesting added discretionary powers in the Department of Health, Education, and Welfare (now the Department of Health and Human Services, or DHHS), the proposal's percentage limits would have affected efficient and inefficient hospitals alike, with the result that greater problems would be created for those hospitals that had already streamlined their operations; likewise, the percentage formula would have allowed expenditures in have-not areas, with a lower base, to grow in smaller increments than expenditures in high-cost areas, widening rather than narrowing the gaps in accessibility to high quality and advanced technology.

While regulatory arbitrariness such as appeared in the Administration's bill can be defended as a way of avoiding the necessity for addressing difficult trade-offs and contesting provider claims, ${ }^{22}$ Congress was troubled by the seeming departure from regulation designed to maintain sensitivity to local needs in favor of an insensitive federal formula. Having been given this powerful demonstration that regulation must be arbitrary if it is to be effective, Congress recoiled and defeated the Administration bill in 1979. While the proposal may still not dead, there is no question that Congress was stimulated by the glimpse it provided of the future under regulation to reconsider whether regulation is in fact the most appropriate strategy. Several of the Congressional leaders in the House's defeat of the Administration proposal have begun actively to pursue the alternative of restoring market forces to a useful role in making the necessary choices. ${ }^{23}$

Yet another development contributing to policymakers' new awareness of competition as a strategy for controlling health care costs is the Federal Trade Commission's recent antitrust enforcement effort in the industry. ${ }^{24}$ Following the Supreme Court's 1975 decision that the so-called "learned professions" are not exempt from the antitrust laws, ${ }^{25}$ the Commission began looking at the medical care sector and commenced a series of investigations into possible antitrust violations. Approaching the industry with the premises of antitrust enforcers, the Commission's staff raised questions and considered issues that had long been neglected in health policy debates. The Commission's efforts were perceived to be inconsistent with prevailing policies and assumptions, giving rise to the question of which approach was the appropriate one. The Commission began to be perceived as a consumer-oriented advocate of competition in health services within the federal government, where competition had previously lacked supporters of any kind. ${ }^{26}$ In this way, the Commission succeeded in reopening questions that had previously been regarded as closed and in giving practical, rather than merely

22. Havighurst, supra note 16.

23. See, e.g., H.R. 7527 (Reps. Richard Gephardt and Dave Stockman) and H.R. 7528 (Rep. James Jones), 96th Cong., 2d Sess. (1980); H.R. 3943 (Rep. James Jones) 96th Cong., Ist Sess. (1979).

24. See generally, Havighurst, Antitrust Enforcement in the Medical Services Industry: What Does It All Mean? 58 Milbank Mem. Fund. Q. 89 (1980); Havighurst, The Antitrust Laws, the Federal Trade Commission, and Cost Containment, 56 Bull. N. Y. AC:AD. Med. 169 (1980).

25. Goldfarb v. Virginia State Bar, 421 U.S. 733 (1975).

26. See Iglehart, Adding a Dose of Competition to the Health Care Industry, 10 NAr'l. J. 1602 (1978). 
academic, significance to the debate over the choice between regulation and competition.

Still another factor contributing to the awakening of interest in adopting a competition strategy in the health services industry was the work of able advocates working outside of government. In particular, Professor Alain Enthoven of the Stanford University Graduate School of Business proposed a "Consumer-Choice Health Plan," a scheme for national health insurance based on competitive principles. ${ }^{27}$ At the same time, Dr. Paul M. Ellwood, Jr., of InterStudy in Minneapolis, and his colleague, Walter McClure, continued their work on behalf of HMOs, and the HMO movement began to be viewed as having competitive vitality. This new view of HMOs as something more than a contribution to pluralism was encouraged by a study by the FTC's Bureau of Economics, which called attention to the potential of HMOs to stimulate competitive responses on the part of the larger delivery system and held out the prospect for effective cost containment stimulated by competitive forces. ${ }^{28}$ Moreover, the efforts of Ellwood and McClure in the Minneapolis-St.Paul area produced a proliferation of HMOs that seemed to lend competitive vigor to the market that had not been seen in the health services industry. ${ }^{29}$ Other markets began to show similar promise of becoming competitive $^{30}$ and it was no longer necessary for advocates of competition to make exclusively theoretical claims. Congress began to pay attention.

While the foregoing developments served to strengthen Congressional interest in competition's promise as an organizing and allocating tool in the health services market, the changing national mood regarding regulation in general was a necessary condition for the shift in policy that appears to have occurred. Increasing dissatisfaction with government in all its aspects and the rampant inflation in the 1970 s have induced unprecedented attention to the high costs that regulation appears to impose on consumers, and significant deregulation efforts have begun in a number of regulated industries. ${ }^{31}$ Shifts in governmental philosophy and new evidence of regulation's shortcomings have apparently made it no longer as true as it once was that Congress thinks reflexively in terms of expanding regulation wherever some economic problem is encountered. A definitive indication of Congress' new attitude is its resolution of its inconsistency, throughout most of the 1970s, in expanding regulation of the health care system while simultaneusly moving to cut back similar regulation in other industries. It was perhaps inevitable that the increasing doubts about regulation in general would eventually spill over

27. Enthoven, Consumer-Choice Health Plan (pts. 1 \& 2), 298 New Exi. J. Mrin. 650), 709 (1978). See also A. Enthoven, Health Plan (1980).

28. U.S. Federal Trade Comm's, Bureau of Econonics, The Health Maintenance Organization AND Its EfFects on Competition (staff report prepared by L. Goldberg and W. Greenberg) (1977).

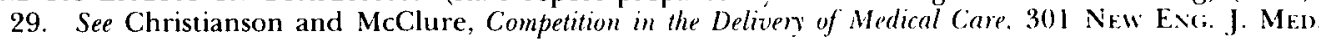
812 (1979); Iglehart, HMOs Are Alive and Well in the Tuin (ities Region, 10 NAlı. J. 1160)(1978).

30. The Hawaii and Portland, Oregon markets are also reasonably competitive. A. Ex [Hovex, HFAl:TH Pl.AN 82-89 (1980).

31. E.g., Airline Deregulation Act of 1978. Pub. L. No. 95-504. 92 Stat. 1705: Motor Carrier Act of 1980, Pub. L. No. 96-296 (July 1, 1980); 94 Stat. 793; Staggers Rail Act of 1980. Pub. L. No. 96-448, 94 Stat. 1895 . 
into Congressional thinking about problems of health policy, but the fact that the health policy debate has finally been brought into tune with the larger deregulation movement is a reassuring sign that Congress knows what it is doing.

II

The Counter-revolution of 1979:

The Health Planning Amendmants (Public: Law 96-79)

The original health planning legislation included no language that could plausibly be construed as charging the health system planner-regulators to consider competition as a factor in their regulatory decisions on certification-of-need. Indeed, the law appeared to be premised on the belief, then prevalent in both planning and policymaking circles, that competition could not make a positive contribution to consumer welfare, the achievement of which necessitates a balancing of competing concerns for cost containment, quality assurance and enhancement, and the accessibility of care. To the extent that competition was recognized by health planners at all, it was seen only as a pernicious contributor to cost escalation, since the nonprice competition among physicians and hospitals that the financing system facilitated was perceived to cause costs to rise without regard to the magnitude of marginal benefits. ${ }^{32}$ Although there was nothing in the law that positively precluded regulators from granting certificates-of-need-that is, allowing entry into the market-on the ground that the resulting competition would have desirable effects, neither did the law do anything to encourage the adoption of such a regulatory approach.

A. Recognizing the Role of Incentives and the

Potential for Change in Financing Mechanisms

The 1979 amendments substantially alter the planner-regulators' mandate with respect to competition. Where previously competition was not mentioned in the law, Congress has now included some extensive findings concerning competition's possible role and made it clear that competition is to be employed wherever it can serve constructive purposes. Most important, the statute and the legislative history reveal a Congressional expectation that competition can indeed, under some market conditions, be useful in achieving the goal of consumer welfare. A striking illustration of Congress' revised view of competition is the Senate committee's revision of the language quoted earlier from its 1974 report. Previously, the committee had expressed the view that "the health care industry does not respond to classic marketplace forces." It now says that the industry "has not to date responded" to such forces. ${ }^{33}$ The key message in the 1979 amendments is that

32. For a discussion of various models of hospital behavior and their effect on quality and cost, see $P$. Feldstein, Health Care Economics 186-216 (1979). The models discussed therein are more complex than those employed explicitly or implicitly by health planners, yet the most plausible do suggest "a bias toward higher 'quality,' meaning more facilities and services, greater capital intensity, and a tendency to introduce new technology before its benefits have been fully evaluated." $I d$. at 196.

33. Compare S. ReP. No. 1285, supra note 10, at 7878 with S. ReP. No. 96, 96th Cong., lst Sess. 52 (1979). 
Congress considers it possible that market forces may be able to do in the future what they have not done in the past and that regulators and planners have a duty to be alert to those possibilities.

The depth of Congress's insight into the possibilities of competition is revealed by the fact that the language endorsing competition was introduced in the same amendments that also substantially removed HMOs from the planner-regulators' jurisdiction. Whereas the original health planning legislation had specifically required the states to subject HMOs to extensive certificate-of-need requirements, ${ }^{34}$ the 1979 amendments undertook, in a dramatic reversal, to prohibit such coverage. This change reflected a belief that, because consumer cost-consciousness in selecting an $\mathrm{HMO}$ in a competitive setting transmitted cost-consciousness to the HMO itself, its investment decisions did not have to be second-guessed. ${ }^{35}$ As important as the recognition of this incentive principle is in the HMO context, it is perhaps more important that Congress, in insisting that regulators give weight to competition in carrying out their remaining regulatory responsibilities, recognized the principle's more general applicability. Thus, Congress refuted the common misconception that competition in health services is exclusively a matter of encouraging HMO development.

In telling the regulators to be alert to the possibility that the market may function usefully in any service, not only those provided by HMOs. Congress was not oblivious to the costly demand distortions that third-party payment can introduce. On the contrary, Congress asked the regulators to be acutely aware of the incentives at work. Thus, the House Committee stated that regulatory intervention might be curbed "if . . . an innovative financing, reimbursement or service delivery arrangement . . were designed so that the method of pavment by patients (1) created incentives for patients to respond to prices charged and (2) placed the providers at financial risk for unnecessary or excessive services." 3 li $^{\circ}$ In this way, the potential for significant, incentive-altering change in the financing system, the root of the industry's current ability to incur unwarranted costs. was recognized as the key to reintroducing market forces into the health services industry. Congress seemed clearly to understand that innovation permitting deregulation would not necessarily be confined to HMO development.

\section{B. The Amendments' Procompetition Language}

Section 1502(b) of the Public Health Service Act, as added by the 1979 amendments, ${ }^{37}$ states Congress' current view of competition's role in allocating health care resources:

(b) (1) The Congress finds that the effect of competition on decisions of providers respecting the supply of health services and facilities is diminished. The primary source of the lessening of such effect is the prevailing methods of paying

34. Public Health Service Act $\$ \S 1523(\mathrm{a})(4)(B)$ (requiring states to regulate "institutional health services") and 1531(5) (defining "institutional health services" to include HMOs), 42 U.S.C. $\$ \$ 300 \mathrm{~m}-2$ $(\mathrm{a})(4)(\mathrm{B})$ and $300 \mathrm{n}(5)(1976)$.

35. H.R. ReP. 190, 96th Cong., 1st Sess. 53 (1979).

36. Id. at 53-54.

37. Planning Amendments of $1979 \S 103(\mathrm{~b})$ [adding $\$ 1502(\mathrm{~b})$ of the Public Health Service Act]. 
for health services by public and private health insurers, particularly for inpatient health services and other institutional health services. As a result, there is duplication and excess supply of certain health services and facilities, particularly in the case of inpatient health services.

(2) For health services, such as inpatient health services and other institutional health services, for which competition does not or will not appropriately allocate supply consistent with health systems plans and State health plans, health systems agencies and State health planning and development agencies should in the exercise of their functions under this title take actions (where appropriate to advance the purposes of quality assurance, cost effectiveness, and access and the other purposes of this title) to allocate the supply of such services.

(3) For the health services for which competition appropriately allocates supply consistent with health systems plans and State health plans, health systems agencies and State health planning and development agencies should in the performance of their functions under this title give priority (where appropriate to advance the purposes of quality assurance, cost effectiveness, and access) to actions which would strengthen the effect of competition on the supply of such services.

The message of these findings is that health services should be divided by the planner-regulators into two categories-those "for which competition does not or will not appropriately allocate supply" and those for which competition is or may become a reliable allocative mechanism. As to resources used in rendering services in the former category, command-and-control regulation should be employed to determine the appropriateness of new investment. As to services that respond to market forces, a more laissez-faire attitude is indicated. Thus, it is no longer appropriate for regulators to assume that command-and-control intervention is required with respect to all services over which they have jurisdiction. Instead, a threshold determination is required concerning the market's efficacy, and an explicit finding of market failure is nearly a prerequisite for substituting the regulators' judgment for that of the marketplace. Moreover, in noting the significance of "prevailing methods of paying for health services" in determining the need for regulation, section 1502 (b) signals the regulators that, in view of the possibilities for change in the financing system, they should not assume that what needs regulation today will necessarily require their regulatory services in the future.

Other provisions in the amendments reveal Congress' preference for competition. To the Act's lengthy list of "national health priorities," which previously lacked even an oblique reference to competition, the amendments add a new desideratum: "The strengthening of competitive forces in the health services industry wherever competition and consumer choice can constructively serve, in accordance with [section 1502(b)], to advance the purposes of quality assurance, cost effectiveness and access." 38 In a less hortatory and more substantive vein, the amendments assign to HSAs the new function of "preserving and improving, in accordance with section 1502 (b), competition in the health service area." 34

Finally, the amendments introduce two new criteria that certificate-of-need agencies are expected to employ in their decision making. First, they are to weigh, "in accordance with section 1502(b), the factors which affect the effect of competition

38. Id. $\S 103(\mathrm{a})$ [amending $\S 1502(\mathrm{a})$ of the Public Health Service Act].

39. Id. $\S 103(\mathrm{c})$ [amending $\S 1513(\mathrm{a})$ of the Public Health Service Act]. 
on the supply of health services being reviewed."40 Second, making explicit the need to focus on developments on the demand side of the market in establishing regulatory policies on the supply side, the amendments also require regulators to consider "improvements or innovations in the financing and delivery of health services which foster competition, in accordance with section $1502(\mathrm{~b})$, and serve to promote quality assurance and cost effectiveness." 11 These new criteria confirm that, before embarking on command-and-control regulation in a particular case, health system regulators must address the threshold issue of whether a market failure exists.

\section{Competition and State and Local Health Plans}

Health planning and certification-of-need are interrelated by the expectation that decisions on certificate-of-need applications will be made with reference to the quantitative specifications of resource needs that are contained in the state and local health plans which the agencies are required by law to promulgate. The 1979 amendments require that these plans be more quantitative than in the past ${ }^{12}$ and also introduce the definitive requirement that decisions on certificate-of-need applications shall be "consistent with the state health plan."4.3 It may appear that the law, by insisting on quantitative health plans, implies that central planning is preferable to competition and is thus internally inconsistent in simultaneously insisting that competition be highly valued.

It would be possible to minimize the practical significance of the 1979 amendments' procompetition language by calling attention to the fact that section 1502 (b) frames the crucial question as being whether "competition appropriately allocates supply [of the service in question] consistent with health systems plans and State health plans." ${ }^{44}$ One could argue that such plans, which, as just noted, the amendments require to be specific and quantitative, are the ultimate reference point for assessing competition's efficacy and that Congress intended that competition should be used only if it was deemed the best way to achieve a particular numerical goal. This would be an extraordinary reading, of course, since competition as an allocative device is a process for discovering and giving effect to consumers' preferences, not for hitting predetermined targets. The allocation of resources resulting from a smoothly functioning market, like the results of the politically accountable system of health planning-cum-regulation, is normally regarded as legitimized by the democratic character of the choosing process itself.

Although regulation and competition can be complementary in many respects, the dominant theme in the health planning amendments and their legislative history is that they are essentially alternative allocative devices whose relative utility varies with the circumstances. This is perhaps the best reason why the results of

40. Id. $\& 103(\mathrm{c})$ [amending $\S 1532(\mathrm{c})$ of the Public Health Service Act].

41. Id.

42. Id. $\S 115(\mathrm{~d})$ [amending $\S 1513(\mathrm{~b})(2)$ to the Public Health Service Act].

43. Id. $\S 117(\mathrm{a})$ [adding $\S 1527(\mathrm{a})(5)$ to the Public Health Service Act]

44. Id. $\S 103(\mathrm{~b})$ [adding $\S 1502(\mathrm{~b})(2)$ to the Public Health Service Act] (emphasis added). 
relying on consumer choice should not be judged by their correlation with the planners' preferences. Congress has also made clear, however, that its preference for competition should be accommodated with careful health planning in a different fashion. Thus, the House committee report addressed specifically the anticipated content of state and local health plans insofar as they deal with services that are deemed by the planners to be allocable by market forces:

[T]he goals of the plan and the statement in those plans of changes in resources which are needed in the area... might differ depending upon the agency's assessment of the extent to which, for a particular service, competition will limit the development of unneeded capacity and protect the public from its costs. For instance, plans could avoid establishing numerical goals or resource requirements by identifying where certain types of services are needed, or appear excessive, or by establishing a range for the number of new services needed. ${ }^{5}$

What Congress intended was that health planners would affirmatively plan for competition, and for possible deregulation, by including in the plans, wherever feasible, explicit findings covering the market's efficacy for controlling the supply of specific services. The regulatory model adopted, while leaving the planners in charge and enhancing the authoritativeness of their plans, also gave them a new mandate to allow competitive forces to determine supply wherever, in their judgment as unbiased planners, competition would more accurately reveal consumers' preferences and would not unduly jeopardize other goals judged more important than the goals that competition serves. Where the planners find the market likely to be serviceable in these terms, the regulators are instructed to refrain from command-and-control regulation of procompetitive new investment and market entry.

\section{Judicial Review of the Role Assigned by Planners to Competition}

Although health planners have a new statutory duty to judge, on the merits and for each type of service, the value of the marketplace as a mechanism for revealing what the public wants, it is not altogether clear how this responsibility will be enforced. It is unlikely that DHHS, wedded as it is to the conventional view of competition's value and desirability, will encourage the planning agencies to adopt Congress' more sanguine view. Moreover, Congress will probably not be perceived to be so singleminded on this issue that health planners will automatically respect its preferences. Thus, unless the courts are in a position to enforce stated Congressional preferences, the effect of the new declaration of competition's desirability may depend on its hortatory value alone. For this reason, it seems appropriate, in an effort to educate planner-regulators on their new deregulatory responsibilities, to include a somewhat technical discussion of the ways in which disappointed applicants for certificates-of-need may obtain judicial review of agency actions affecting competition.

In fact, there appears to be some question whether the courts will have an adequate opportunity to review health planners' conclusions on competition's value

45. H.R. REP. No. 190, supra note 35 , at 53 . 
with respect to particular services. If such conclusions are embodied, either explicitly or implicitly, in a state's health plan, ${ }^{45 a}$ a state certificate-of-need agency's decision to deny certification on the ground of inconsistency with the plan might not be appealable on the basis that the plan's determination of competition's undesirability was not based on evidence or reasoned findings. Although principles of administrative law usually allow attacks on agency rules that are inconsistent with the statute being implemented, the case here is peculiar in that the "rule"-if the state health plan (SHP) can be analogized to a regulation-is not the product of the same agency whose decision is being reviewed. Indeed, the state agency would not have access to or be able to provide to a reviewing court the full record on which the SHP was based. For these reasons, ordinary judicial review of certificate-of-need decisions would not permit the court to assess whether Congress's declared preference for competition had been given due weight in determining the outcome.

The remedy of a certificate-of-need applicant whose competitive entry is foreclosed by the SHP is to seek review of the SHP itself. This would have to be done administratively in the first instance, probably by applying to either the HSA or the Statewide Health Coordinating Council (SHCC), depending on where the SHP was in the three-year cycle of review and revision. Under the 1979 amendments, the applicant appears to be legally entitled to a hearing and a reasoned decision, supported by evidence, on his claim that compeition would be valuable with respect to the particular service, and in the particular market, in question. " Judicial review to determine whether this right had been accorded might be deemed appropriate at either of two points. One possibility is that review would be allowed in federal court under federal law upon the HSA's contrary determination, on the theory that the HSA's health systems plan (HSP) was essentially final and open for revision by the SHCC only on matters affecting "statewide health needs." Alternatively, the SHCC might be deemed the final decision maker, so that review would be granted, in state court under state law, only after that state instrumentality had acted. ${ }^{48}$ In either event, the decision maker would have 10 show that a record had been made that supported the outcome.

Although Congress has made no provision for judicial review of the actions of either the HSA or the SHCC and has not made clear which is the final decision maker on localized issues, the better view would seem to be that the HSA. as a nongovernmental body, gives only recommendations: otherwise, a severe problem of unconstitutional delegation of legislative porer to a private entity would exist."

\footnotetext{
45a. In its commentary on regulations implementing the 1979 plaming amendments, DHHS "emphasizes that it is through the development of plans that planning agencies should determine whether a specific health service responds to competitive forces, not through individual determinations as [certificate-of-need] applications are being reviewed." 45 Fed. Req. 69740, 69771 (1980).

46. Planning Amendments of $1979 \$ 116(\mathrm{~b})$ [amending $\$ 1532(b)(6)$ of the Public Health Service Act].

47. Public Health Service Act \& 1524(c)(2)(A).

48. The planning law does not refer to the SHCC: as a state instrumentality but contemplates that the Governor will (1) appoint the members of the SHCC: (although at least 60) percent of the members are chosen from lists of nominees submitted by the states HSAs): (2) select the SH(C.'s chairman with the advice and consent of the State Senate: and (3) exercise a veto oser any draft State health plan that he "determines does not effectively meet the statewide health needs of the State as determined by" the state certificate-of-need agency. Public Health Service Act $\S 1524$, as amended.
}

49. See, e.g., Simon v. Cameron, 337 F. Supp. 1380 (C.D. Cal. 1970). 
A consequence of this reading would be to make the SHCC responsible for according due process to would-be competitors' claims that market forces should be allowed to operate with respect to particular services. Because, as later discussion demonstrates, this matter is amenable to proof by specific evidence, a hearing and findings of fact are appropriate. Moreover, because Congress has provided a clear legal standard for application to the facts surrounding a particular service, the SHCC's function in making the definitive choice between regulation and competition that is required by sections $1502(\mathrm{~b})(2)$ and (3) is clearly adjudicative, not legislative, thus triggering due process requirements and the availability of judicial review. ${ }^{50}$ On similar reasoning, opponents of competition should be given standing to oppose provisions of the SHP that would encourage it.

The 1979 amendments' substantial changes in the character and responsibility of the SHCC, by giving it more formal status as an agency of state government and new duties to afford hearings and to decide disputed issues, would seem to confirm the view that the SHCC's decisions in promulgating the SHP are final and reviewable agency actions. The result is that aggrieved certificate-of-need applicants may, in some instances, have to pursue their rights, not before the state agency, but before the SHCC. Even though the peculiarities of this amalgam of regulation and planning make it hard to predict with certainty whether, where, and how the courts will intevene, judicial review of the SHCC's rulings on competition's value and efficacy should be available. The 1979 amendments, in addition to strengthening the planner's hand by making the SHP conclusive on such matters as competition's role, also formalized the planning process so that it would not effectively foreclose private rights. Congress thus left the courts in a position to review, on appropriate application, the planners' disposition of claims to the effect that Congress' preference for allowing competition to operate wherever it is efficacious had been violated.

It remains to be seen, of course, whether state courts will be at all insistent on furthering Congress' desire that compeitition be given a fair hearing on its merits in formulating parts of the SHP. It is perhaps probable that most of them will defer to planners' conventional assessments, but, as the federal courts have done from time to time in reviewing administrative action, they may sometimes be able to prevent the planners from selling out competition too quickly." Some substantive outcomes may therefore be affected. Nevertheless, it must be recognized that the courts cannot be counted on to revolutionize health planning. The ultimate

50. $\$ 116(\mathrm{~d})(3)$ of the Planning Amendments of 1979 amends $\$ 1532(\mathrm{~b})$ of the Public Health Service Act so as to make a state agency's final decision on a certificate-of-need request subject to judicial review in the state courts. $\$ 116(\mathrm{~d})(3)$ goes on to say that the requirement for judicial review "may, as appropriate, apply to other review programs." Among the other review programs discussed in $\$ 1532$ are those carried out by the SHCC. Judicial review of SHCC decisions on the state health plan would certainly seem "appropriate" since the 1979 planning amendments make the state health plan binding on certificate-of-need agencies. Planning Amendments of $1979 \S 117$ (a) [adding $\$ 1527(\mathrm{a})(5)$ to the Public Health Service Act]. It would be odd to grant judicial review of state agency decisions but not of the SHCC decisions that underlie them.

51. E.g, Continental Air Lines, Inc. v. CAB, 519 F.2d 944 (D.C. Cir. 1975); Northern Natural Gas Co. v. FPC, 399 F.2d 953 (D.C. Cir. 1968). 
check on anticompetitive regulation must be political. Whatever their precise legal meaning, the procompetition provisions in the 1979 amendments may only be important if they are backed by political as well as occasional legal sanctions.

\section{E. The Policy Significance of the New Regulatory Mandate}

Taken together, the procompetition amendments of 1979 fundamentally alter the character and thrust of the health planning and certificate-of-need enterprise. Whereas the command-and-control mentality and the idea of allocating resources through central planning previously supplied the health planning law's sole foundation, the law now embraces a mix of strategies and gives clear instructions to the planners and regulators that allocation by market forces is $t o$ be preferred if it can reasonably be expected to serve the public well.

The legal and policy significance of the new regulatory mandate can perhaps be most fully appreciated in the light of more general developments in regulatory reform at the federal level. Among the recent regulatory reforms and proposals reflecting policies toward regulation and competition that are similar to those embodied in the health planning amendments are: President Carter's 1978 executive order directing executive-branch agencies to weigh the economic impact of regulatory initiatives ${ }^{52}$ and several pending legislative proposals to extend similar regulatory analysis requirements to independent regulatory agencies. ${ }^{53}$ Though similar to those initiatives, the health planning amendments seem somewhat better calculated to make a real difference in regulatory outcomes. Because those other measures were triggered in large part by concern over the high compliance costs occasioned by some "social" regulation-that is. controls to protect health and safety and the environment-they less clearly establish that the restoration of competition is also a paramount regulatory objective. Moreover, because the mandates in those measures are not industry-specific, the regulators will find it easy to conclude that the message was intended for someone else. Finally, the reform measures reflect some reluctance to allow the courts to review specific regulatory actions in the light of the new instructions, and thus the message is largely hortatory, depending for its effectiveness solely on what it may convey to the agencies about the attitudes of their political overseers. The health planning amendments, on the other hand, being industry-specific. enforceable in court, and reflecting an emerging seriousness in Congress about competition in the health sector, would seem to be of a substantially different order. Indeed, Congress appears to have departed very far from its customary practice of leaving the regulators' mandate vague and internally inconsistent, thus forcing them to make the hard policy choices.

Although many regulatory reform proposals have been addressed primarily to the need for benefiv/cost analysis in health and safety and environmental regulation, there has also been explicit recognition of a need to assure that regulation

52. Exec. Order No. 12,044, 3 C.F.R. \& 152 (1978 Compilation).

53. E.g., S. 262, S. 755, and H.R. 77, 96th Cong., lst Sess. (1979). For a discussion of these and some similar bills, see Symposium On the New Regulatory Reformers, 3 REcicl.Airox 17 (1979). Proposals comparable to those listed will undoubtedly be considered by the 94th Congress. 
does not suppress competition any more than is necessary. This theme has most recently appeared in a bill offered in late 1979 with such wide bipartisan support that its passage in some form seemed a reasonable prospect. ${ }^{54}$ The Regulatory Flexibility and Administrative Reform $\mathrm{Act}^{55}$ would require federal agencies, before adopting a policy or rule, to consider its "effects on competition"iti and to make "a finding that the policy or rule is the least anticompetitive alternative legally and practically available to the agency to achieve its statutory goals." 57 This latter mandatory finding would be subject to judicial review. ${ }^{i 8}$ The new requirements to maintain competition are specifically directed to agencies that are engaged in economic, as opposed to social, regulation.

Although S. 2147 would not apply, by its terms, to the health planning and regulatory agencies contemplated in Public Law 93-641, its mandate is essentially the same as that already incorporated, according to the foregoing analysis, in the 1979 amendments. The requirement that health planners and regulators assess, with respect to each particular service, the market's efficacy as a resource allocator corresponds directly to the reformers' proposal to require that "economic regulatory agencies ... choose the least anticompetitive alternative when issuing a major rule or policy." 59 Two proposed legislative findings incorporated in S. 2147 state the same general presumption favorable to competition that is reflected in the health planning amendments:

(9) in the normal course of events, the free market is the appropriate means for allocating goods and services and has proved to be the most effective means of regulating the economy;

(10) to encourage competition and innovation, government regulations should not impose needless entry barriers to the marketplace. ${ }^{\text {(ii) }}$

At the time the 1979 amendments were adopted, there was no other federal regulatory statute-with the possible exception of recent airline legislation ${ }^{61}$ - that was as explicit and compelling in its mandate to promote competition as the health planning legislation. Given this state of the deregulation art and the extraordinary difficulty of introducing competition in health services, it appears that Congress took just about the longest step it could possibly have taken wrard the goal of deregulation of the health sector. While it remains to be seen how far toward that goal it will be possible to go, the law is surprisingly clear. Nevertheless, it is by no means certain that a change in the statutory formulation of a regulatory mandate can make much practical difference. Indeed, the practical significance of the procompetition language in the 1979 amendments depends ultimately on many other matters, including the willingness of planner-regulators to honor its intent,

54. But see Clark, Regulatory "Reform" May Lose to Regulatory "Revolution" Advocates. 12 NAT'L J. 969 (1980).

55. S. 2147 , 96th Cong., 1st Sess. (1979).

56. Id. $\S 641$.

57. Id. $\$ 641(\mathrm{a})(4)$.

58. Id. $\S 628$.

59. Id. $\& 64 \mathrm{l}(\mathrm{a})(4)$.

60. Id. $\& 101(9)(10)$.

61. Airline Deregulation Act of 1978, Pub. L. No. 95-504, 92 Stat. 1705. 
the true potential of competition as an allocator of resources in the health sector, and the willingness of Congress to take some other steps to improve competition's efficacy. The remainder of the article attempts to shed light on some of these imponderables.

\section{III}

\section{Thinking Concretely About Market Failure \\ As a Rationale for Command-and-Control Intervention}

The thesis of this article is that the health care system's planner-regulators, before exercising their jurisdiction to limit entry and restrict competition in a particular category of health services, should assess the affected market's actual and potential ability to allocate resources of the particular type involved. If competition appears to be a reasonably reliable social control mechanism under all the circumstances, then regulation should foster it rather than supplanting it by command-andcontrol intervention. Wholehearted acceptance of this simple conceptualization of the regulators' task would greatly affect the regulatory agenda, the nature of health planning, the substance of many regulatory decisions, and, in the long run, the nature of the health care system as a whole. Although it has been argued above that the planner-regulators are now under an enforceable statutory duty to adopt essentially the recommended approach, this discussion is concerned as much with persuading health planners of the logic of the approach as with telling them their legal responsibilities. In fact, more progress in increasing competition's role in the industry can be anticipated from the creative efforts of a minority of plannerregulators who share a belief in its potential efficacy than from judicial enforcement of the new statutory mandate against regulators who are disinclined 10 accept it.

The starting point in educating planmer-regulators to competitions potential is a careful diagnosis of the market's past failure to impose due constraints on the escalation of costs. Certificate-of-need requirements have been imposed primarily as a response to the distortions of the demand for medical care that are perceived to flow from the availability of third-party payment. But. While this general rationale has substantial validity, it does not finally establish the necessity for quantitative determinations of need with respect to every facility or service within the regulators' jurisdiction. In fact, many different circumstances surrounding a particular service and its financing may reduce the need for such command-andcontrol regulation, particularly if an adjustment for regulation s own shortcomings is made on the proregulation side of the regulatory balance. In order to appreciate the significance of specific characteristics of health services and their financing that affect the need for command-and-control regulation. it is important to understand the market failure to which regulation is addressed.

A. The Problem: Not Third-Party Payment Itself. But Inadequacies in its Design

There is a pervasive assumption that third-party payment is itself the market failure that necessitates governmental intervention and that, because third-party financing of some health care is inevitable, so is regulation. The underlying idea is that health insurance, though clearly needed to protect people against unpredictable 
costs, is so destructive of cost-consciousness at the point of consumption that price competition becomes impossible, leaving only cost-escalating nonprice competition to operate. If the analysis stops here, with the recognition of what economists call "moral hazard" 62 - a costly phenomenon that is associated with insurance of all kinds-the case for intervention seems strong. But this is the point where analysis should begin, not end. While a full critique is impossible here, a few essential points can be made. ${ }^{63}$

Precisely because of the moral hazard problem that consumers face in insuring themselves against health care costs, one could reasonably expect several things to happen in a competitive market with normal incentives. ${ }^{i t}$ First, because the cost of insuring is raised by moral hazard, consumers would not purchase insurance against all risks and would instead bear more of them personally: they would also be inclined to obtain fuller coverage of those services that are nondiscretionarysuch "necessities" as orthopedic care for broken bones-than of services whose consumption depends primarily on how cheap they are. Second, competing health insurers, seeking to provide the most cost-effective coverage, would take steps to limit the exposure of the insurance fund, using techniques analogous to-but, due to obvious circumstantial differences, different from-the use of claims adjusters and multiple estimates in automobile collision insurance. The challenge to find better ways to control costs would lead in many directions, but the universal objective would be to discover optimal combinations of strategies for dealing with moral hazard while providing good quality care and essential financial protection. Thus, the design of health insurance benefit packages and the administration of claims in a competitive market would take into account the complex trade-offs among such factors as the extent of particular risks, individuals ability and willingness to bear risk, the price elasticity of demand for various services (that is, the exposure to moral hazard), and the administrative costs and acceptability of various cost-containment methods.

If private insurers could not design efficient systems for controlling moral hazard, alternative delivery systems, such as HMOs, might turn out to do the job better and succeed to the insurers' business. While the necessity for meeting price competition in the market for prepayment plans supplies the essential discipline, the key to the cost-containment success of alternative delivery systems is their closer integration of the financing and the delivery of care. Such integration reduces the third-party effect by bringing providers, whose decisions ultimately determine costs, under some kind of central control by a cost-conscious health plan operator. Internal management arrangements in an alternative delivery system can take many different forms, including a direct employer-employee relationship, a contract embodying understandings on prices and administrative requirements, inter-

62. See Pauly, The Economics of Moral Hazard, 58 AM. EcoN. REx. 531 (1968).

63. For a more extended discussion of why the market has failed to control health costs and how market forces might be strengthened, see Havighurst, Controlling Health Care Costs: Strengthening the Private Sector's Hand, 1 J. Health POL., PoL'Y \& L. 471 (1977).

64. For more extended discussion of what consumers and their insurers might do to control moral hazard, see Havighurst \& Hackbarth, Private Cost Containment, 300 NFw Ex(:. J. Mr.1). 1298 (1979); Havighurst, Professional Restraints on Innovation in Health Care Financing, 1978 Dike. L.J. 303, 321-35. 
nal peer-review mechanisms, or some carefully designed incentive arrangement. Insurers could themselves organize alternative delivery systems by getting providers to accept contractual requirements or by separately rating provider groups that have their own methods of internal discipline. It will be noted that the HMO concept, as it has evolved, does not encompass all of the mechanisms that a competitive market might yield to deal with the cost problem. ${ }^{65}$

With this wide variety of techniques available for controlling costs without undue sacrifice of other values, the competitive market would seem to have considerable potential for accommodating the complex trade-offs that exist. Precisely because no "ideal" solution can be identified and because different consumers and providers will prefer different arangements, the competitive process has important advantages over command-and-control regulation. Which tends to seek "one right way." For all these reasons, the presence of third-party parment in the market is not, by itself, a sufficient justification for regulatory intervention.

\section{B. Identifying the True Causes of Market Failure}

The conclusion that third-party payment alone does not justify regulation does not necessarily constitute an argument for regulation's immediate repeal. The point is not that there is no market failure requiring policy makers attention but. rather, that its nature is considerably different from what is commonly understood and that its causes must be looked for at a deeper level.

As the previous discussion implies, the market for health services and the market for health insurance or other forms of financial protection cammot work well-and, in particular, cannot achieve the needed closer integration of financing and delivery-unless certain fundamental conditions are satistied. First consumers must have a strong incentive to choose health plans that effectively control costs. Second, health insurers must be free to design coverage and administrative arrangements in the consumer's interest. And. thibd. alternative delivery svstems must have unrestricted market opportunities so that they can be organized to supply any lacks in the third-party system. It is the failure of the matret to satusfy these conditions in the past that accounts for the felt need for regulation. Bit By the same token, the increasingly strong possibility that these conditions are beginning to be satisfied in a few markets, and will be satisfied more fully and in more markets in the future, makes it necessary that the health care system's plannerregulators consider closely whether their regulatory services are in fact needed in specific circumstances.

The stated prerequisites for efficient performance in the privately financed sector have not been met in the past for essentially three reasons. which together

65. For descriptions of some innovative health plans that depart from the standard HMO model, see

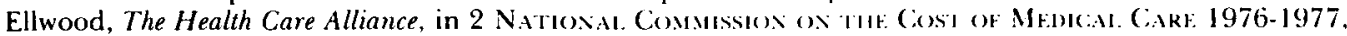
153 (1978); Enthoven. Shattuck Lecture-Cutting Cost Without Cutting the Quality of Care. 298 Niw Exc: J. Men. 1229 (1978); Evans, Physician Based Croup Insurance: A Proposal for Medical Cost Comtrol. 320 Nrw Enc. J. Men. 1280 (1980); Gumbiner, Prior Authorization Ciuts Hospital Cests. Nata. Underwritt.r l0 (May 3, 1980); Moore, Cost Containment Through Risk-Sharing by Primany-Care Phrsicians, 300 Nril Exc. J. MED. 1359 (1979).

66. Havighurst, supra note 63 
account for the market failure that has occurred. First, federal tax law has strongly biased consumers toward buying comprehensive "first-dollar" coverage and discouraged insurer cost-containment efforts. As a tax-free fringe benefit, employerpurchased health insurance permits employees' health care expenses to be paid with untaxed dollars, providing a strong incentive to buy more than the optimal amount of insurance. ${ }^{67}$ From another perspective, the tax law dilutes the value to the consumer of any savings that the insurer might achieve through cost-containment efforts and the employer might pay out as additional wages. Because a dollar saved is not a dollar earned, insurers will be less inclined to eliminate questionable payments.

Second, most decisions on insurance coverage are not made by the consumer, but by employers and unions, whose own interest in maintaining a beneficent image in the employees' eyes may cause them to act against the employees' true interests. Thus, in facing the trade-offs between more insurance coverage and more take-home pay, an employer or union leader may act either politically, emphasizing to the rank and file the visible benefits and obscuring the hidden costs, or paternalistically. Either way, the effect is likely to be that the decision maker places a higher value on comprehensive, hassle-free coverage than would the employee if he or she were offered a chance to economize. Congress is currently considering proposals to require that employers offer employees several health plans, making the same contribution regardless of the plan chosen. ${ }^{\text {is }}$ The purpose would be to give each individual a meaningful opportunity to make an economizing choice. Variations on this proposal would allow some of the savings from such an economizing choice to be received tax-free, "whereas other proposals would place limits on the exclusion of emplover-paid premiums from taxable income. ${ }^{70}$ Thus, significant changes are possible in the area of consumer incentives. $^{71}$ Even without such legislation, however, the market already has begun to feature greater cost-consciousness than in the past, and an increasing number of employers now offer their employees a range of choices in health care benefits. These private developments are contributing to a gradual weakening of the premises on which regulation is based.

The third significant cause of the insurance market's failure to respond to consumers' cost concerns is the effectiveness of privately imposed restraints of trade that have inhibited the market's performance from the beginning. ${ }^{2}$. The

67. Feldstein and Friedman estimate that the exclusion of employer-paid premiums from employee taxable income and wages means that group insurance can be bought through the workplace at a discount of almost 35 percent. Feldstein \& Friedman, Tax Subsidies, the Rational Demand for Insurance and the Health Care Crisis, 7 J. Pub. ECON. 155, 156 (1977). Even after the insurer's administrative expenses are deducted (expenses which replace costs that patients and providers would have to bear), the discount on services purchased is still substantial.

68. E.g., H.R. 5740, S. 1485, and S. 1590, 96th Cong., Ist Sess. (1979). Similar bills will be before the 97 th Congress.

69. E.g., S. 1590 .

70. E.g., H.R. 5740 .

71. For example, the Congressional Budget Office estimates that S. 1590 would cause employees to choose less extensive health insurance benefits, thus reducing private medical spending by $\$ 10$ to $\$ 15$ billion in 1985. Congressional Budget Office, Cost Estimate for S. 1590 (March 17, 1980).

72. Havighurst, Professional Restraints on Innovation in Health Care Financing. 1978 Dikf. L.J. 303. 
medical profession and the hospital industry have effectively shaped private third parties' methods of doing business, preventing them from becoming aggressive purchasers of services and thus from triggering provider competition based on price, efficiency, and willingness to cooperate in cost containment. ${ }^{73}$ Moreover, the provider community in most markets has prevented various alternative delivery systems from having easy access to the market. ${ }^{74}$ Because of the restraints imposed, the market has been unreceptive to innovations addressed to the cost and moral hazard problems. Current efforts to enforce the antitrust laws in the health care industry may shortly break down the most substantial barriers to competition, allowing the insurance industry and alternative delivery systems to evolve in the directions indicated by consumer preferences. ${ }^{75}$ While much remains to be done in clarifying the law and bringing providers to account, the greater problem may now lie in overcoming insurer inertia ${ }^{76}$ and free-rider problems ${ }^{77}$ that discourage attacks on the barricades.

What needs to be observed here is that the market failures that have prevented the health insurance market from meeting consumers' needs may all be remediable. The antitrust enforcement effort has already begun to eliminate the most clear-cut professional abuses, and it will soon be considerably more difficult than it is today to argue that the market is not revealing consumers' true preferences. Indeed, in several markets already, alternative delivery systems are well enough established and consumers have enough competitive options that the need for any entry regulation at all is open to question. ${ }^{78}$ Although one could argue that command-and-control regulation must dominate the system as long as the tax law is not changed and consumer choice remains restricted in some employment settings, the legislative choice not to change those competition-limiting conditions need not be deemed to render market forces wholly unreliable. As long as private

73. See, e.g., Indiana Fed'n of Dentists, No. 9118 (FTC, March 25, 1980) (administrative law judge held that Indiana Federation of Dentists was founded as part of an organized effort to impede insurers' cost-containment efforts); Michigan State Med. Soc'y, No. 9129 (FTC, filed July 27, 1979) (FTC alleges that the Michigan State Medical Society organized a boycott of an independent Blue Shield plan that undertook unwanted cost-containment efforts). See also Havighurst \& Kissam, The Antitrust Implications of Relative Value Studies in Medicine, 4 J. HeAlTh POL., POL'Y \& LAW 48 (1979) (suggesting that professionsponsored relative value studies violate the antitrust laws in part because they suppress independent insurers' cost-containment initiatives). But see United States v. American Soc'y of Anesthesiologists, 473 F. Supp. 147 (S.D.N.Y. 1979) (held that a profession-sponsored relative value study did not violate the antitrust laws).

74. See, e.g., Am. Med. Ass'n v. United States, 130 F.2d 233 (D.C. Cir. 1942), affd, 317 U.S. 519 (1943) (criminal conviction for anti-HMO activities upheld); United States v. Halifax Hosp. Med. Center (D.C. Fla. 1980), 5 Trade Reg. Rep. (CCH) \ 50,748 (proposed consent decree barring anti-HMO activities); Forbes Health System Med. Staff, [1976-1979 FTC Transfer Binder] Trane. Rec: ReP. (CCH) I 21,587 (FTC File No. 7810009, June 27, 1979) (proposed consent decree barring anti-HMO activities). For a case study in how the medical profession has disciplined innovative plans, see Goldberg and Greenberg, The Effect of Physician Controlled Health Insurance: U.S. v. Oregon State Medical Society, 2 J. Health Pol., Pol'y \& Law 48 (1979).

75. Supra note 24.

76. Havighurst, supra note 72 , at $336-42$.

77. See M. Pauly, The Role of the Private Sector in National. Healih Ixsirance 37-38 (1979).

78. See Christianson \& McClure, supra note 29. 
restraints are curbed, the private market can function reasonably well even if the tax law continues to distort incentives and somewhat affects the equilibrium that market forces seek.

The implication of these observations for regulation is that market conditions can no longer be presumed to require command-and-control interventions in all cases. In keeping with their new Congressional mandate, the planner-regulators must consider much more than merely whether third-party payment exists. They must also ask whether it still takes forms that fail to protect consumers from moral hazard, whether innovation in the financing system is still restrained, whether it is unreasonable to expect third parties to address a specific cost problem, and whether consumers have enough alternatives available to constrain effectively the performance of the third-party payers and the providers whose costs they underwrite. More generally, they must ask themselves whether, given the new opportunities for evolution toward more cost-effective types of insurance coverage and alternative financing and delivery mechanisms, it is right for regulation to retard that desirable evolution by intervening to shield inefficient insurers (and their customers) against the consequences of their failure to innovate. Later discussion suggests that the most responsible regulatory policy will sometimes be to withdraw such protection, allowing competitive pressures to induce insurers and consumers to seek new forms of insurance coverage or alternative delivery arrangements. It should be clear that regulation could easily become-and should strive to avoid becoming-the sole remaining source of market failure, shoring up obsolete, dysfunctional financing mechanisms and barricading the avenues of change.

IV

Weighing "Factors Which Affeci The Efrici of Competition"

Since command-and-control regulation is not warranted simply by the availability of some third-party payment, attention must be directed to specific characteristics of a service and its financing that affect the need for central allocative decisions. The 1979 amendments instruct the regulator to consider, as a threshold issue, "the factors which affect the effect of competition on the supply of the health services being reviewed." 79 The following discussion sets forth a list of such factors useful in appraising existing market conditions. However, in considering whether the market is currently capable of performing well, the planner-regulators should not lose sight of the potential for change in traditional payment mechanisms that may alter the need for regulatory intervention. Later discussion argues not only that the planner-regulators should make allowances for future developments but that they should actively encourage such change-even to the extent of withdrawing regulatory controls that protect the private sector against the need to change. Throughout the rest of the article, the reader will detect an urgency about using regulatory powers sparingly wherever the competitive private sector could, if it would, better perform the cost-containment job.

79. Planning Amendments of $1979 \S 103(\mathrm{c})$ [amending $\$ 1532(\mathrm{c})$ of the Public Health Service Act]. 
A. The Burden of the New Responsibilities

Although analysis of the appropriateness of command-and-control regulation in specific circumstances can be a complex undertaking, the planner-regulators' inquiry into this new and unfamiliar set of questions should not add excessively to their overall regulatory burden. If the regulators' analyses are carried out in good faith and if market-strengthening activities are also undertaken, the result should be to narrow significantly the range of the regulators' command-and-control activities. To the extent that portions of the health services market can be left to market forces subject only to general oversight, the planner-regulators would be free to concentrate on regulating in those areas where their services are most neededhospital beds, for example-and on efforts to improve the functioning of market forces through consumer education, information dissemination, and encouragement of innovation in the financing system.

There is also reason to expect that day-to-day regulatory burdens will not be greatly increased by the new necessity for weighing competition's efficacy. Once basic understanding has been achieved, many services can be categorized as allocable or not by market forces without extensive data collection and close analysis. Moreover, the local health systems plan and the state health plan can incorporate findings on the efficacy of competition with respect to each type of service, thus reducing the need to address the issue on a case-by-case basis.

Although it cannot be denied that the new responsibility to foster useful competition adds to the complexity of the planner-regulators' task, that is not a valid reason for not assuming it or an argument for misreading or misapplying the new statutory mandate. Obviously, the best way to simplify the regulators task is to hasten the transition to a system in which consumer incentives and competition do operate effectively. Thus, health planners' efforts to encourage financing system reforms could improve the quality of residual regulation. Changes in the tax laws, antitrust enforcement, and legislative efforts to widen the range of consumer choice would also be desirable, and, with the new regulatory mandate, such public measures to improve competition would be less likely to have their beneficial impact blunted by anticompetitive regulation.

\section{B. Characteristics of a Service and Its Financing that Affect the Need for Command-and-Control Regulation}

The following discussion briefly sets forth nine specific "factors which affect the effect of competition" and which would thus be relevant in any assessment of the vitality of the market as an allocator of health services of a particular type. Although the natural tendency of many regulators will be to pick and choose among the listed factors to find support for the result they desire to reach, responsible regulation requires consideration of the entire list. Weights must of course be varied according to the circumstances, and the factors should not be used merely as a checklist but should serve as a guide to the exercise of judgment on the ultimate question: whether, under all the circumstances, the encouragement of competition would be in the public interest as Congress has defined it. 


\section{A Statutory Distinction and its Questionable Relevance}

\section{Institutional versus noninstitutional services}

It is possible to read section $1502(b)^{80}$ as putting "inpatient health services and other institutional health services" permanently on the agenda for command-andcontrol regulation, since that section seems to characterize such services as being among those "for which competition does not or will not appropriately allocate supply." Although it will be tempting for health system planner-regulators to read this language as establishing a conclusive presumption against competition's efficacy for all but noninstitutional services, this reading seems incorrect in view of legislative history indicating, with specific reference to institutional services, that a change of the financing system might obviate the need for regulation. ${ }^{81}$ Moreover, there is no current policy basis for distinguishing between institutional and noninstitutional services, particularly as those services are defined in the statute. On the contrary, dysfunctional payment methods, while they do apply more pervasively to some inpatient services, are applicable to services of all types and affect some noninstitutional services more than some institutional ones. ${ }^{82}$ On balance, the distinction between institutional and noninstitutional services seems the beginning, not the end, of the analysis.

\section{Factors Related to Financing}

a. The scope of third-party payment

If third-party payment does not cover the service to a substantial enough degree to induce significant abuse, the planner-regulators should deem demand factors not to preclude competition. In judging whether third-party payment is too widespread to trust the marketplace, it is also appropriate to focus on whether the scope of third-party payment is being dictated by consumer choice or is instead a reflection of insurers' or providers' collective interests. While the current weakness of competitive bargaining at the interface between traditional health care plans and providers suggests that command-and-control regulation may well be justifiable under prevailing conditions, the next factor invites exploration of circumstances of health plan operation that might point to a different conclusion.

\section{b. The character of third-party payment}

The market's efficacy would be most obvious in a market in which all care was provided through competing closed-panel HMOs, but other types of health care plans could also be expected to cope with the moral hazard problem well enough to obviate public oversight. ${ }^{83}$ It is not enough, however, simply to observe that all

80. See text accompanying note 37 supra.

81. H.R. REP. No. 190 , supra note 35 , at 53-54.

82. The definition of "institutional health services" found in $\$ 1531(5)$ of the Public Health Service Act includes all routine outpatient services of a hospital. Certain expensive outpatient diagnostic services provided in physicians' offices would seem to present a greater danger of abuse of the financing system. Nursing home services, less often paid for on a cost-reimbursement basis, may also present fewer problems than some noninstitutional services.

83. Havighurst \& Hackbarth, supra note 64. 
plans must be marketed competitively, since. even thougl it might be assumed that they cannot automatically pass on cost increases. interplan comperition signifies very little if the plans are not able or do not choose to procure providers services on a competitive basis. Thus, it is only to the extent that health care plans are both motivated by competition to control costs and free to purchase needed inputs competitively, that they and the providers doing business with them do not require regulatory oversight.

Indicia of effective health are plan competition in the procurement of provider services include, in particular, the use by competing insurers of provider participation agreements that specify both price and administrative requirements necessary to implement utilization controls and coverage limitations. But inmorations that effectively restore the demand side's disciplinary capability need not be even this radical. Thus, insurers might use deductibles or coinsurance 10 an extent leaving consumers responsible for paying many costs out of pocket and thus cost-conscious enough to deter many provider price and cost increases." A greater impanc on the moral hazard would result if particular benefits were paid on a fixed-clollar basis. leaving consumers conscious of the marginal dollat and thus with an incentive to seek out providers willing to provide the service for less. ${ }^{\text {sin }}$ Insurers. provider groups, and others were relatively free to organize health care alliances and to use participation agreements and other measures that seemed cost-effective. it would not be essential that all care be paid for under such arrangements or through HMOs before one could conclude that the matket was capable of allocating resources well enough. Indeed, it is argued later that the potentiality of innovative payment methods may alone obviate command-and-control regulation.

c. Who bears the cost burden of obsolete facilities:

One theory that has been widely used to justify portectionist entry controls in regulated industries is that because existing lacilities' capilal costs must be paid for by consumers in any event, allowing new competition that renders existing facilities obsolete may be unduly costly to the public as a whole. "it this theory has often been employed in health sector regulation in frustrate such competitive developments as the construction of ambulatory surgical facilities. Which are deemed to drain patients away from existing hospitals without reducing their overhead. On the other hand, Congress grant of a broad exemption from certiticate-of-need requirements to HMOs may be deemed to reflect at least a partial rejection of this theory, since HMOs' chief economizing skill is in substituting outpatient for impatient care. ${ }^{87}$ The impact of $\mathrm{HMO}$ competition on existing hospitals, and on those committed to pay their capital costs, was apparently not a matter that Congress viewed as a decisive consideration.

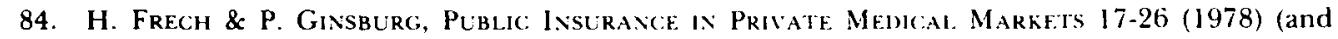
sources cited therein).

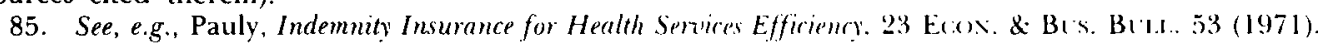

86. See Havighurst. supra note 9, at 1156-58.

87. Luft, How Do Health Maintenance Organizations Achime Their Sanings? 298 Niw Exc. J. Mrs. 1336 (1978). 
The 1979 amendments did, however, expressly authorize the planner-regulators to consider, as one factor in their certificate-of-need decisions. the impact of new construction projects "on the costs and charges to the public of providing health services by other persons." ${ }^{88}$ This language leaves regulators free to direct attention to the way in which the capital costs of providers adversely affected by new competition are handled by the financing system. The planner-regulators attention is thus drawn to the crucial question of whether the financing system reimburses providers for the cost of obsolete facilities. The inquiry here is complicated, and a final judgment may depend on a technical analysis of cost-reimbursement formulas (for example, is overhead allocated on the basis of the actual or some assumed level of occupancy?) and of indemnification techniques (for example. do cost sharing and indemnification limits foster enough price competition to prevent costs of obsolete facilities from being freely passed along:).

\section{Additional Characteristics of the Seritice Itself}

\section{a. Nondiscretionary versus discretionary services}

If demand for a particular service would not be much affected by changes in price-that is, if the service is a "necessity" and not discretionary"-then the fact that it is covered by third-party financing should not much affect its consumption." On the other hand, if new entrants are offering more costly iensions of the same essential service, a different aspect of the moral hatard problem would be presented."

88. Planning Amendments of $1979 \$ 116(\mathrm{~g})$ [amending $\$ 1532(\mathrm{c})(9)(\mathrm{B})$ of the Public Health Service Act].

89. Strictly speaking, medical care is best understood as a continuum that camnot simply be divided into the categories "necessary" and "unnecessary" or "discretionary" and "nondiscretionary." Although either end of the continuum is care that is clearly necessary (nondiscretionary) or unnecessary (discretionary), in the middle there is a vast gray area reflecting. among other things, scientific uncertainty about the efficacy of various treatments and diagnostic tools and differences in the personal characteristics (physiological, psychological. and emotional) of patients. Moreover, if all medical services are to be dichotomized, the only meaningful categories would distinguish services whose benefits exceed their costs from services whose costs exceed their benefits. Sep Havighurst \& Blumstein, Coping uith Quality/Cost Trade-offs in Medical Care: The Role of PSROs. 70 Nw. U. L. REx. 6. 9-20 (1975). See also A.

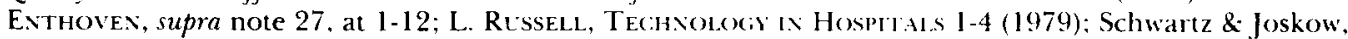
Medical Efficacy Versus Economic Efficiency. 299 NEw E.vo. J. Mr.D. 1462 (1978). Obviously, the valuation of benefits necessary for such categorizations would be extremely difficult.

90. The responsiveness of demand to changes in price (the price elasticity of demand) varies considerably among medical services. For example. the demand for ambulatory care is significantly more elastic than demand for inpatient hospital care. Phelps \& Newhouse. Coinsurance, the Price of Time, and the Demand for Medical Services, 56 REv. Ecos. \& S1AT. 337 (1974). However. most studies of demand elasticity do not disaggregate demand beyond distinguishing between outpatient and inpatient services. Even so, it seems clear that price elasticity would vary for different inpatient services. Sef Havighurst,

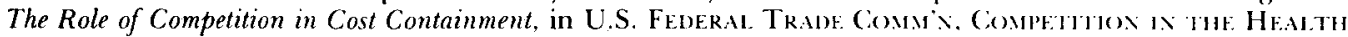
CARE SEcTor, supra note 12, at 361-63. An obvious example of a nondiscretionary inpatient service (with a correspondingly low price elasticity) is emergency surgery to repair the damage done by trauma.

91. The same essential service might be made more costly in any number of wavs. In the case of emergency surgery, for example, the patient's stay in the hospital might be lengthened. more expensive diagnostic tests might be used, the number and quality of the attending staff might be increased, or the hospital room made more pleasant and comfortable. Some or all of these added increments of "quality" might increase the probability that the patient will fully recover. Nevertheless, it would be difficult to characterize them as "necessities;" and certainly they are "discretionary." 
The added increments of "quality" might not themselves be necessities, yet, if the third-party financing system were ready and willing to reimburse the added costs, entry controls might seem appropriate. Nevertheless, the better means of cost containment in the case of such nondiscretionary services would seem to be for the third parties to limit what they will pay for each essential service on the basis of what the service could be obtained for from an efficient provider." If If the consumer were thus given an incentive to evaluate cost differentials, plannerregulators could conclude that allowing free entry into the provision of such services would allow low-cost providers at least to begin to compete with high-cost providers. With such alternatives available, third-parties might more quickly perceive the benefits of reimbursing providers or patients on some basis other than costs incurred. Conversely, restrictions on entry would have the effect of conferring a franchise on existing providers, putting pressure on third parties to cover their high costs.

Not all health services are nondiscretionary, of course. Indeed, some are so discretionary in all cases that their coverage by health insurance seems inappropriate. ${ }^{93}$ Because third-parties have available the strategy of totally excluding such services from coverage or subjecting them to heavy copayment requirements, regulation of the supply of such discretionary services by certificate-of-need might seem unnecessary to protect against over-utilization induced by third-party payment. ${ }^{94}$ Of course, such strategies may not be widely used because of tax considerations, legal requirements, or administrative problems in drawing lines. In this event, regulation will appear appropriate, but it should still be deemed desirable-and possibly feasible-in the long run to allow the supply of such services to be allocated by the market.

The case for entry regulation is perhaps strongest where, judging in benefit/cost terms, the service is nonessential or discretionary in many cases but nondiscretionary in others. ${ }^{95}$ Coverage of the service by third-party pavers would be appropriate only in the cases dictated by clear medical necessity, but for the health care plan to distinguish one case from another would often require complex administrative mechanisms. Where such strategies are not cost-effective, regulatory intervention to limit the supply of the service and bring about its rationing by proviclers will seem plausible. ${ }^{96}$ Nevertheless, planner-regulators must consider whether, even though

92. Pauly, supra note 85 .

93. Cosmetic plastic surgery (other than to repair damage from trauma) is often cited as an example of a highly discretionary service.

94. For example, if insurers exclude purely cosmetic surgery from coverage or subject it to heavy copayments, regulators can safely permit free entry of ambulatory plastic surgery facilities.

95. Many, if not most, services fall into this category. It is often alleged, for example. that many more hysterectomies and appendectomies are performed than are "necessary." Yet, in some cases, hysterectomies and appendectomies are clearly "necessary" and "nondiscretionary."

96. Of course, the regulatory tools for limiting the provision of such services may be even less reliable than the insurer mechanisms. Certificate-of-need regulators can limit the supply of surgical beds and facilities but they cannot be assured that the limit will reduce the number of "unmecessary" procedures. Although the process by which hospitals ration services and facilities is poorly understood, it seems unlikely that only the least cost-effective procedures are wrung out of the system when an external constraint is imposed. Indeed, the allocation of reduced hospital resources will often be 
practical measures seem available, special considerations have prevented third parties from adopting them. Desirable innovation might be discouraged by fear of provider displeasure and retaliation, the natural disinclination of oligopolists to compete in new and potentially disruptive ways, ${ }^{97}$ the probability that rapid imitation will deprive the innovators of a significant competitive advantage, and the likelihood that some of the benefits of innovation will not be captured by the innovator but will instead, as in the case of an innovation that favorably affects the standard of medical practice in the community, accrue to others. ${ }^{98}$ Possibly the system's resistance to desirable change in such circumstances can be identified as a market failure warranting health planners' intervention. It is suggested, however, that the planners consider intervening to break up the logjam rather than simply seizing on the market's temporary recalcitrance as an excuse to assume a command-and-control role.

b. The nature of substitutes for the service in question

Sometimes, the substitute service that is likely to be used when a regulationcreated supply constraint is encountered is more expensive than the competing service being regulated. 99 When such a circumstance occurs, it invalidates a basic assumption underlying certificate-of-need requirements-namely that reducing the availability of a service will result in the use of less costly alternatives and savings to the community. This problem is presented almost any time the proposed new facility or service is one that substitutes for costly hospital care. Of course, if the hospital bed supply has itself been closely tailored to fit the community's needs, then it may be reasonable to expect the system as a whole to find ways to assure that patients are treated in the surroundings most appropriate to their specific condition. But hospital beds of each type are unlikely ever to be under such tight control. ${ }^{100}$ Moreover, providers lack incentives and tools to allocate existing supplies to patients strictly in accordance with medical need. In the real world, therefore, regulatory discouragement of lower-cost competitors may be quite destructive. Indeed, the scarcity of such lower-cost alternatives will make it harder for the planner-regulators to control the growth of the hospitals themselves.

In most of the cases in which these problems are encountered, there will also exist the more commonly observed risk that the moral hazard will induce inappropriate utilization of the service in question by patients whose alternative is a

determined by nonmedical considerations-for example, the prestige that various services bring to the hospital.

97. Havighurst, supra note 72 , at $336-42$.

98. M. PAULY, supra note 77.

99. For example, if regulation unduly limits the supply of nursing home beds, patients best cared for in nursing homes might have to be cared for in hospitals. Similarly, if the supply of home health services is restricted, patients might be forced to remain in nursing homes longer than necessary.

100. The Carter Administration contended that, despite the ongoing efforts of health planners and certificate-of-need regulators, there were 130,000 unneeded hospital beds in the United States. As a result, the Administration developed a package of new initiatives designed to limit federal financial support for unnecessary hospital construction. Federal Support for Hospital Construction in Overbedded Areas, 45 Fed. Reg, 83,701 (1980). 
lower-cost (rather than a higher-cost) service. In such cases, the regulators must compare the benefits and costs of regulation very carefully. In their assessments, they must not neglect to consider the ways in which the financing plans can themselves affect the system's performance by seeking correct placement of their beneficiaries.

\section{c. The presence of capital investment}

While third-party payment can induce inappropriate utilization and price escalation for all types of services without regard to their capital intensity, capital investment creates special claims on the future that regulation can appropriately seek to minimize. First, the existing financing system embodies a tacit and incomplete, but still strong, commitment to reimburse providers for capital costs. ${ }^{\text {(1)1 }}$ Second, hospital rate-setting regulation, largely borrowed from the public utility field, often embodies the same commitment to cover capital costs-at least when a certificate-of-need agency approves the investment. ${ }^{102}$ Third, regulatory bodies of all kinds, reflecting a bias toward fairness at the expense of efficiency, have long indulged the "suck-cost obsession," which causes them automatically to reject any competitive developments that would reduce the present value of regulated firms' investments. ${ }^{103}$ Finally, the political process is probably more responsive to claims that investments would be devalued and bricks and mortar rendered obsolete than to claims of less tangible consequences flowing from strengthened competition.

Health services that do not involve significant capital investments, such as home health services, do not threaten to freeze the system because they are not frozen in place. In an increasingly competitive market, they can expand or contract with relative ease. Moreover, they do not present the same risk of embarrassment that the planner-regulators face when a bricks-and-mortar facility is admitted to the market today and rendered obsolete by market forces tomorrow. Precisely because their admission to the market creates less of a political-economic barrier both to market-inspired innovations and to regulatory changes of direction, new health services that involve negligible capital outlays are less in need of strict command-andcontrol regulation than other facilities and services.

d. The benefits of nonprice competition

Where price competition is ineffectual due to passive third-party payment, competition may still play a constructive role in stimulating providers to strive for improved quality, increased efficiency, and greater patient convenience and satisfaction.

101. See, e.g., J.Feder, Medicare: The Politics of Federal Hospital Insurance 57-60 (1977); Wolkstein, The Impact of Legislation on Capital Development for Health Facilities, in HEALTH Care CaPITAL: Competition and Control 7, 8-11, 21-25 (G. Macleod \& M. Perlman eds. 1978).

102. Bauer, Hospilal Rate Setting-This Way to Salvation?, in Hospital. Cost Containient: Selected Notes for Future Policy 324, 348 (M. Zubkoff, I. Raskin. \& R. Hanft eds. 1978). The hospital cost containment legislation drafted by the Senate Committee on Labor and Human Resources in the 96th Congress would have allowed hospitals to pass-through the costs of all new projects granted certificates-ofneed. That bill was not passed by the full Senate, however.

103. R. Noll, Reforming Regulation: An Evallation of the Ash Colicil. Proposal.s 25-26 (1971). 
Because competition could be highly beneficial in promoting these values, regulators might be expected to establish the seriousness of countervailing hazards before engaging in exclusionary regulation. This conclusion should hold even though certificate-of-need requirements were introduced in large part because competition in health services tended to focus on nonprice factors and thus to have powerful cost-escalating tendencies. Congress explicitly recognized the value of nonprice as well as price competition in the 1979 amendments, when it embraced competition wherever it could "constructively serve . . . to advance the purposes of quality assurance, cost effectiveness, and access." ${ }^{104}$ It would seem that the benefits of such competition are great enough that the regulators should be willing to tolerate some uncertainty concerning cost impacts and even some limited cost increases in order to obtain them.

The possible benefits of nonprice competition include improvements in the quality of care, including not only the technical quality and intensity of services, but also amenities and accessibility. Quality-promoting competition can also stimulate efficiency in the use of resources, since, as long as there is any limitation on providers' ability to pass on particular costs, the pressures of nonprice competition will force providers to employ available resources to the consumer's advantage. In many circumstances, a strong argument can be made to the effect that nonprice competition, because it stimulates attention to consumer needs and preferences and induces the husbanding of resources so as to satisfy those needs and preferences better, is preferable to no competition at all. ${ }^{105}$

\section{The Availability of Alternative Ways of Controlling the Service's Cost \\ The existence of nonmarket controls on cost}

Given the benefits that may be derived from nonprice competition, plannerregulators might encourage it if the risk of cost escalation were deemed not to be great. One reason this risk might be acceptable is the existence of regulatory or other nonmarket controls over both price and utilization. State hospital rate regulation might be an inadequate protection, since many such programs are tied closely to institution-specific costs and rely primarily on certificate-of-need determinations to settle the legitimacy of the costs that a hospital wishes to pass on. On the other hand, the well-regarded program in Maryland has largely ignored planning decisions in rate setting. ${ }^{106}$ This approach, plus rate setting that attaches only limited weight to a particular institution's actual costs, would permit the planners to encourage competition without fear that the public would be burdened with excessive costs. Although the Carter Administration's original hospital cost containment proposal would have provided a backstop justifying more widespread use

104. Planning Amendments of $1979 \$ 103(\mathrm{a})$ [amending $\$ 1502(a)$ of the Public Health Service Act].

105. For example, anecdotal evidence suggests that nonprice competition in San Francisco's physician services market has made doctors more responsive to their patients and improved the accessibility of care. Chase, Will Surplus of M.D.s be Good for Patients? Look at San Francisco, Wall St. J., March 13, 1980, at 1, col. 1 .

106. See Demkovich, Tough-Minded Cost Control Commission Keeps Lid on Maryland Hospital Rates, 11 NAT'L J. 1361 (1979). 
of procompetitive strategies, a later version of the federal "cap" legislation would have permitted automatic pass-through of the costs of all projects granted certificates-of-need. ${ }^{107}$

Government also seeks to control costs by various limitations on the price that it will pay for services rendered to beneficiaries of public programs, such as Medicare and Medicaid. While cost reimbursement is the dominant method of payment in these programs, there are some additional limits on what will be paid. Limitations to reasonable costs have been introduced for hospitals under Medicare, ${ }^{110}$ and some state Medicaid programs pay nursing homes prospectively determined rates that are not adjusted to cover actual costs. ${ }^{109}$ Such rate controls might be deemed, in specific cases, to diminish fears of cost-escalating impacts on public programs enough to warrant an increase in beneficial nonprice competition.

Admitting a new service to the market as a competitive stimulus also raises the risk that utilization could be inappropriately expanded. Though existing controls over utilization practices are highly incomplete and of questionable value, "they might be deemed to reduce the risk of serious over-utilization enough to permit some competitive developments.

\section{$\mathrm{V}$ \\ Market-Forcing Rrgitation: \\ Dereglation as a Simcites To Neribris Rrfora}

\section{A. Choosing a Regulatory Strategy}

The most radical position that health system planner-regulators might take is that, in view of the availability of private cost-containment techniques, price and utilization would be better controlled by competing financing plans and that entry controls can never adequately serve the public. On this premise, they would essentially withdraw from regulating new market entry and new investment on the basis of need and focus their regulatory efforts only on preventing monopoly. The goal of such deregulation would be to seek fundamental change exclusively through the unleashing of market forces. It is not at all clear that this radical strategy would be irrational. Little evidence, after all. supports the effectiveness of

107. The Senate Committee on Labor and Human Resources drafted such a pass-through provision, but the revised bill was not reported to the Senate floor. As a result, no committee report on the bill was filed and no official version of the pass-through provision is available for purposes of citation.

108. Social Security Amendments of $1972 \S 223$.

109. $3 \mathrm{CCH}$ Medicare and Medicaid Glide, I 15,504 el seq.

110. See, e.g., Havighurst \& Blumstein, supra note 89 (criticizing the Professional Standards Review Organization program which reviews utilization by Medicare and Medicaid beneficiaries and some privately insured patients); Havighurst, supra note 72, at 377-81 (suggesting that "foundations for medical care" sponsored by the medical profession and providing utilization review services to private insurers may not be aggressive enough in their cost-containment efforts and in fact may pose an anticompetitive threat). See also Demkovich, The Physician Peer Review Program-Does It Cost More than It Saves?, 12 Nat'l J. 733 (1980); PSROs: Are They Worth What They Cost?, MEt). Worı.1) Nkws 45 (July 21 , 1980). But see Egdahl, Taft, Friedland, \& Linde, The Potential of Organizations of Fep-for-Service Physicians for Achieving Significant Decreases in Hospitalization, 186 ANisis of Stritkr 388 (1977). 
supply-side controls to keep costs and prices down or to squeeze inappropriate utilization out of the system. ${ }^{11}$

Although a "let-'er-rip" policy could be defended as a responsible regulatory strategy, the mere theoretical possibility of private cost-containment efforts may be too speculative to warrant its adoption. Such a laissez-faire policy depends on strong, untested assumptions and is unlikely to work well without major change in tax or other governmental policies and without effective antitrust enforcement. ${ }^{112}$ In any event, it is almost certainly inconsistent with the regulators' statutory mandate. The amended health planning legislation makes it quite clear that a policy of deferring to market forces must be justified on the basis of reasonable expectations that such forces can and will serve the public adequately. Moreover, case law involving other regulated industries indicates that, while regulators must give competition its due weight as a substitute for regulated monopoly, it cannot be embraced without stated reasons and without evidence indicating a probability that the public will be well served by competition in the specific case. ${ }^{13}$ Legally, therefore, health system planner-regulators may be authorized to allow competition to operate only where an affirmative justification, supported by evidence, is given. Although Congress might be well advised to repeal the health planning legislation as part of a broader strategy for letting market forces take over, ${ }^{114}$ as things now stand, this is not an option that the regulators may adopt themselves. The evidence necessary to support a policy of instantaneous and total deregulation of all services is probably not yet available in any market. ${ }^{115}$

Far from leaning toward the radical laissez-faire approach, most health system planner-regulators will tend toward conservatism and resist accepting any responsibility at all for fostering competition. Although they may acknowledge a duty recognize competition whenever and wherever it becomes a potent and constructive force, most of them will regard that event as so unlikely to occur that it can be dismissed for practical regulatory purposes. This assessment of competition's prospects is partly an outgrowth of health planners' training and ideology and partly a result of political pressures and the planners' need to obtain the cooperation of existing providers. The planner-regulators will not perceive the highly conservative nature of their position because the possibilities of fundamental change will have escaped their notice. Moreover, in doing battle with established interests on minor incremental issues. they will not realize the extent to which they have adopted their

111. See note 15 , supra.

112. For an overview of a more complete strategy for promoting competition, see C. Havighurst, Increasing Competition in Health Services, March 28, 1980 (prepared for a conference on National Health Policy held at the Hoover Institution in Palo Alto, California). See also A. ExTHovex, supra note 27, at 114-56.

113. See FCC v. RCA Communications, Inc., 346 U.S. 86 (1953); Hawaiian Tel. Co. v. FCC, 498 F.2d 771 (1974).

114. At least one of the procompetitive proposals for national health insurance would repeal the planning law outright. H.R. 1010, 97th Cong., 1st Sess. (1981).

115. Although the reports of vigorous competition in Minneapolis-St. Paul are encouraging (see Christianson \& McClure, supra note 29), instantaneous and total deregulation may not be justified even there. 
antagonists' assumptions concerning the rate and nature of contemplatable change and have allied themselves with those with whom they share power. ${ }^{116}$ It is noteworthy that planners and providers share many similar views on the efficacy of competition and the desirability of its encouragement.

A slightly more market-oriented approach that planners might adopt also lies toward the more conservative end of the scale. It would involve undertaking a careful and open-minded evaluation of the nine factors itemized above and of the effectiveness of existing price and utilization controls in private financing plans and would employ a competitive strategy only where market forces and such controls were found to be working well. The trouble with this strategy is that it accepts the market as it finds it and neglects even the most immediate and realistic possibilities for change. More seriously, it implies that the financing system is, at any point in time, doing all that it can reasonably be expected to do and that further cost containment is the regulators' sole responsibility. This approach would tend to freeze dysfunctional reimbursement practices in place, an effect that would be compounded if regulation were really effective in moderating costs. Thus, to the extent that regulation successfully protected existing financing plans from the consequences of their own inefficiency, it would ipso facto reduce both traditional plans' incentive to change and the market opportunities of alternative delivery systems. For these reasons, the regulatory attitude that looks only at the financing system as it is currently performing may be viewed as precisely the problem that must be overcome. Given significant possibilities for competitive evolution in the financing system, regulation must be implemented in such a way that it serves as a catalyst of change, not as the private sector's best excuse for not changing.

Unfortunately, it is simply not possible for the planner-regulators to be neutral on the private sector's future cost-containment capability. While it would undoubtedly be easier for them to say that they will recognize that capability when and if it appears, current decisions that are based on the assumption that the prevailing market failure is irremediable, or on the assumption that it can be cured without the planners' participation, could easily seal the fate of private sector change. On the other hand, a willingness to leave some things to market forces today would strengthen those forces and permit them to assume an increasingly substantial role in the future. Thus, because whatever prophecy is implicit in the regulators' basic approach could easily be self-fulfilling, the planner-regulators, unless they choose to be part of a market-oriented solution, could themselves be part of the market failure that is the ultimate problem. The ensuing analysis seeks to help the planner-regulators carry out their regulatory responsibilities in such a way as to promote rather than suppress competition's emergence. It would seem that they have been explicitly charged by Congress with a duty to approach matters in these terms.

\section{B. The Strategy of Anticipating and Encouraging Change}

Fortunately, a moderate approach, seeking fundamental change under regulatory supervision, is available to the health care system's planner-regulators. The proposed

116. Havighurst. supra note 9. at $1178-88$ and $1194-97$. 
strategy, foreshadowed in earlier discussion of the financing system's potential for change, involves anticipating what the market can effectively do and withholding regulation that inhibits the market's adaptation. While this strategy is certainly the most difficult to employ for both political and technical reasons, its rewards are potentially great.

In assessing the possibilities for such demand-side reforms as competitively inspired controls over the price and utilization of services, planner-regulators should not attach undue weight to conventional assessments or to the predictions of those with a stake in keeping financing arrangements as nearly as possible in their present form. Most providers, most insurance carriers, most administrators of public programs, and even most established HMOs are not likely to be receptive to significant additional changes in financing and delivery arrangements. At best, these interests appear to favor gradual, incremental changes, presided over by regulators with whom they can negotiate the pace of change and the details. By their very nature, competitively inspired developments, in addition to lacking the by-your-leave character of most regulation-sponsored change, are to some extent unpredictable and sudden, and they are thus intensely threatening to established industry interests. For these reasons, competition lacks a political constituency and able advocates within the industry and is systematically deemphasized as a possibility in the conventional wisdom. ${ }^{117}$ Although their political makeup and environment will make their efforts on behalf of competition difficult, the HSAs and state certificate-of-need agencies have an important role to play in keeping this promising idea alive and giving it a chance to show what it can do.

The argument here is that the private financing system's potential for change must be a central factor in every regulatory decision on whether to impose the regulators' own quantitative standards in controlling entry or, alternatively, to let market forces regulate entry, location, and survival. Perhaps the most significant fact about the health services marketplace today is that the private sector's capacity to introduce innovative cost-containment measures is increasing steadily. Wider availability of HMOs, greater cost-consciousness on the part of employers and unions, active antitrust enforcement against provider-imposed restraints that have inhibited change in the past, and emerging legislative interest in increasing consumers' opportunities to economize in the purchase of a health care plan all point toward a dynamic potential that planner-regulators can help to foster-and should certainly not ignore-in their regulatory activities. As the financing system begins, at long last, to respond to consumers' cost concerns, supply-side regulation must adjust to allow market forces to operate where they have previously failed to do so. Further, as the planner-regulators recognize the potential for competitive responses even where they have not yet occurred, they have a responsibility not to stand in the way of such developments.

The recommended regulatory stance should be assumed not as a rigid position, but as a part of a broad and constructive planning strategy designed to effectuate

117. Cf. Enthoven, Does Anyone Want Competition? The Politics of National Heallh Insurance, in New Directions in Public Health Care 238-50 (C. Lindsay ed. 1980). 
the new national health priority of strengthening useful competition and HSAs' newly assigned function of "improving . . . competition in the health service area."118 Thus, where the planner-regulators take the view that the price and utilization of a particular service can be better controlled in the private sector than through entry regulation, they might also find it appropriate to preside over the transition from public to private control in order both to stimulate the process of change and to assist affected parties in adjusting to it. For example, rather than simply opening up the market for such a service, they might announce their intention to do so at some future date-thus, the health systems plan might declare, "In two years, anyone can have a CAT scanner." Then the planners could actively assist employment groups, insurers, PSROs, and the rest of the community to prepare for that day, when effective price and utilization controls could be embodied in fee schedules and in coverage limitations in the insurance contract and implemented through provider participation agreements.

In pursuing a strategy for bringing about needed change, the planner-regulators could give their attention to overcoming a problem likely to be encountered in obtaining wider use of participation agreements by indemnity insurers-namely, providers' recalcitrance in accepting contractual limitations on their fees or on their right to payment for unauthorized services. If not the result of an actionable restraint of trade, ${ }^{119}$ such resistance to competition might best be met by the planners' announcing their willingness to allow new entry by any new provider who had firm agreements embodying price and utilization understandings with third parties. Such a tactic should give third parties, who could threaten to exclude providers without such contracts from eligibility to provide covered services, the bargaining power necessary to bring providers to terms. The dynamic at work here is the same one that supports allowing substantial HMOs to build their own hospitals without regulatory restraint. The new exemption for HMOs from certificate-of-need requirements ${ }^{120}$ strengthens greatly their ability to bargain effectively with existing institutions. ${ }^{121}$ The crucial message is that planners who come to appreciate the dynamics of competition should be able, if they are willing, to force providers to accept competition against their will.

Without health planners' active intercession in support of financing system change, the prospect for innovation by third-party payers may be considerably diminished. Even though it may be obvious that insurers could take effective measures that consumers would value, there may not be an adequate incentive for any single private insurer to take the needed first step. No innovation is without

118. Planning Amendments of $1979 \$ 103(\mathrm{c})$ [amending $\$ 1513(\mathrm{a})$ of the Public Health Service Act].

119. In Am. Med. Ass'n., No. 9064 (FTC, Oct. 12, 1979), the FTC ruled that the medical profession's ethical proscriptions against "contract practice" violated section 5 of the Federal Trade Commission Act, 15 U.S.C. $\$ 45($ a) (1)(1976). Nevertheless, antipathy to such arrangements is deeply ingrained in many physicians and can be expected to endure.

120. Planning Amendments of $1979 \S 117(\mathrm{a})$ [adding $\S 1527(\mathrm{~b})$ to the Public Health Service Act]

121. The new ability of certain HMOs to build a hospital without regulatory approval threatens existing facilities with competition that previously they could count on being suppressed. The competitive pressure should induce them to sell or lease to, or contract with. the HMO. Paradoxically, the exemption for HMOs should lead to little new construction. but better use of existing facilities. 
risk, and this kind may incur the wrath of organized medicine. Moreover, it will certainly entail some costs in negotiating with providers, in selling the innovative plan to employment groups, and in introducing new administrative procedures. Finally, the benefits of the innovation may accrue to others besides the innovator and his customers. Thus, for example, it might have spillover effects on medical practice generally, changing doctors' approach to treating all their patients and not just those insured by the innovating insurer. Alternatively, other insurers might find it relatively easy to imitate any innovations that proved effective, leaving the innovative firm to bear the costs of unsuccessful ventures without much hope of gaining a competitive advantage from a successful one. All of these possibilities may make it unrealistic to expect competition alone, unaided by the health planners, to bring about some desirable and highly beneficial innovations. ${ }^{122}$

Where insurers seem unable to capture a distinct competitive advantage from introducing certain cost-containment innovations, the planner-regulators, rather than seizing on the apparent market failure as an excuse for command-and-control regulation, might take strategic actions of a nomregulatory kind. Directly addressing the market failure itself, they might attempt to trigger the process of change that the unassisted market was unable to get started. For example, their intervention might take the form of actively assisting the marketing efforts of any insurer that seeks to alter its payment methods-in effect, subsidizing the insurer by reducing his costs and risks in innovating. Another alternative would be for the plannerregulators to cooperate with several insurers and the state insurance commissioner in simultaneously redesigning the insurers' coverage and approaches to claims review. Any collective action by competing insurers that might be involved, if done under supervision and properly confined to overcoming the identified market failure, should not offend antitrust principles. ${ }^{12: 3}$ Given the arguable market deterrent to individual insurers' initiatives, these market-assisting approaches might be more constructive than direct regulation of supply.

Even where a local market appears hopelessly noncompetitive and private cost containment is not immediately in prospect, permanent regulatory control of entry might still not be the appropriate remedy. Because competition may still be the best long run hope and because nonprice competition could contribute significantly in the short run to quality and efficiency in local markets for health services, the planner-regulators might choose to encourage competition while addressing fundamental market conditions that may in time stimulate the private sector to develop mechanisms for handling the cost problem. Competitiveness is determined by such supply-side factors as: the number of sellers; the availability of information;

122. See M. Pauly, supra note 77 .

123. This point is not clear, however. Under National Soc'y of Professional Eng'rs v. United States, 435 U.S. 679, 696 (1978), the test is whether concerted action "promotes" competition. Under this principle, efforts to overcome a market deficiency such as the free-rider problems identified here may be permissible so long as the effect is to make the market work better and not to prevent its working. The FTC, though declaring ethical prohibitions against advertising and solicitation unlawful, has allowed professional groups to continue to prohibit and police "false and deceptive" advertising, presumably on the ground that consumer ignorance and gullibility is a market failure whose correction by concerted action will make market forces more reliable. Am. Med. Ass'n. No. 9064 (F.T.C., Oct. 12, 1979), at 58-60. 
the existence or absence of collusion; the interchangeability of services and the availability of substitutes for particular services; opportunities for granting hidden price or other concessions as competitive moves that are difficult for competitors to discover and imitate; and private actors' freedom to innovate without fear of sanctions imposed collectively by competitors or others. Where competition has traditionally been weak, it may not be inevitably so, and plannerregulators at the local level might seek to trigger competition by taking nonregulatory steps to encourage aggressive negotiating by insurers (or employers or unions) and to break up collusive practices. They might also stimulate advertising and other forms of information dissemination, such as better disclosure of which providers would "accept assignment"- that is, accept various financing plans' fee schedules or other allowances as payment in full. There are many reasons to think that HSAs and their planning staffs might provide the greatest service to their communities by stimulating price and other forms of competition, by educating consumers and employers to private cost-containment possibilities, and by strengthening those forces that are most capable of offsetting providers' market power and giving effect to consumers' concerns about cost.

Ultimately, planner-regulators might be inclined to lift all entry controls on the basis of the simple availability in the community of a significant number of competitive health care plans with developed cost-containment capability. Once such plans exist in sufficient numbers to give the consumer meaningful options, it should seem appropriate to let the market strategy work. The lifting of controls in such a competitive environment should further strengthen consumers' incentives to join an innovative plan, entrepreneurs' incentives to organize more such plans, and providers' incentives to participate in them. If Medicare beneficiaries have the means, under new legislation, of enrolling in an HMO (or in any other type of competitive health care plan) and benefitting themselves from any resulting saving, ${ }^{124}$ there would no longer be any convincing reason to protect the Medicare program or those beneficiaries who elect not to switch. The planner-regulators would simply have to judge what was a meaningful range of choice, whether competition, both among plans and among providers for the chance to serve the subscribers of such plans, was truly vigorous, and whether the plans would be capable of accepting increased enrollment if costs in the deregulated private sector should rise. If conditions are right, however, deregulation should cause no significantly increased costs, because would-be certificate-of-need applicants (and their lenders) would be deterred from making inappropriate investments by their recognition of the risks that newly effective market forces have created.

\section{VI}

Obstacles to Derfoliation in Healith Srovichs

The idea of moving toward greater reliance on competitively inspired private sector cost controls in the health services industry is an attractive one in many

124. Under H.R. 4000 and S. 1530, 96th Cong., 1st Sess. (1979), a Medicare beneficiary would have the option of enrolling at federal expense in a qualified HMO in lieu of having his or her benefits paid out on a fee-for-service basis. HMOs would compete for enrollments by using any gains from superior 
respects, but it is far from being a simple matter. Not only will many plannerregulators instinctively distrust competition both ideologically and as a threat to their power and prerogatives, but there are severe practical problems in reordering incentives, removing restraints on private initiatives, and restoring competitive instincts long suppressed. Moreover, deregulation must confront two major features of the health services industry that are largely dependent on the continuation of regulation. Both relate to the ways in which society has chosen to finance services for those unable to pay for them.

A. The Relevance of Federal Programs' Comparative Inflexibility

Given recent alterations in the climate for privately initiated change. the private sector's adaptability to deal with artificially induced demand for services and with the higher prices that insurance encourages may be substantially greater than that of public programs such as Medicare and Medicaid. These programs are fixed in law and custom, are unwieldy in size, reflect bureaucratic inertia, and embody a political and social consensus that limits their ability to respond readily to changes in the economic environment. The issue thus arises whether health system planner-regulators must adopt attitudes toward competition that accommodate only the specific needs of federal programs. If regulation were thus geared to the lowest common denominator-the system's least flexible parts-the prospects for meaningful change and reduced dependence on regulation would be greatly diminished. If, on the other hand, the regulators should pursue procompetitive policies in contemplation of significant private sector change, the federal programs, being less adaptable in the short run, may incur some higher costs. Something of a dilemma is thus presented.

The mandate of the planner-regulators extends to the health care system as a whole, and it would not seem appropriate for them to confine themselves to acting in the interests solely of the Medicare and Medicaid programs if that meant inhibiting reforms beneficial to consumers in the private sector. Of course, DHHS may not encourage health planning and regulators to take a long run, system-wide view. ${ }^{125}$ Nevertheless, the Department's stance should not be determinative. Its perceptions are greatly influenced by its fiscal concerns as steward of Medicare and Medicaid funds and by the cost-reimbursement dogma incorporated in these huge programs. Congress, on the other hand, in enacting the planning law and its amendments, has revealed wide concerns and has now squarely endorsed the concept of procompetitive change in the private sector. It would seem that this is the cue that health system planners and regulators should take. Admittedly, HSAs may find it difficult to ignore the preferences and regulatory philosophy of DHHS, to which

efficiency to reduce Medicare cost sharing for the beneficiary or to expand his or her benefits.

125. The final regulations implementing the 1979 amendments are not without promise, however. They seem to suggest that DHHS will show considerable deference to state and local judgments on the desirability of competition and will not pressure state and local agencies to protect Medicare and Medicaid. 45 Fed. Reg. 69,740, 69,771 (1980). 
they are accountable in many respects. But the federal statute, the state certificate-ofneed law, and the state agency are all superior authorities, and one should expect that responsible policies will not be frustrated.

It is also probable that strengthened competition in the private sector will prove to be in the long run interest of the federal govermment's programs. Those programs have many mechanisms within them that would allow them to derive indirect benefits from positive developments in private sector cost containment. Thus, if "usual and customary" fees are kept down through strengthened competition, public programs and their beneficiaries would benefit. Further. any increased institutional efficiency that is brought about by competition should show up in due course in Medicare cost reports. And changes in utilization patterns in treating private patients should ultimately be reffected both in medical practice generally and in PSRO norms that limit the exposure of federal programs. Current proposals to allow Medicare and Medicaid beneficiaries 10 enroll in HMOs at reduced expense to the federal government demonstrate another way in which private sector developments can accrue to the advantage of federal programs.

Private sector reforms, both by showing the way and by reshaping the industry along more cost-effective lines, would almost certainly contribute more to fundamental change in public programs than anything that (ongress of DHHS can reasonably be expected to do by legislation or regulation. Even if Medicare and Medicaid do encounter some higher costs under freer competition. that effect should simply induce Congress and the states to break finally with the costreimbursement approach in those programs and to move to more responsible payment methods. Moreover. if competition does take hold in the private sector, government would be more likely to resist the temptation to control costs by becoming a dictatorial monopsonist, demanding adherence to its fee schedules and "reasonable cost" determinations and otherwise exerting its buving power over providers. With competition working, the government could more readily move toward a voucher-type system in which consumers with subsidized purchasing power and incentives to economize would guide the system. Govermment could thus build on, rather than undercut, the private sector's strengths. In the last analysis, encouragement of private sector changes is probably the shortest route to realiable cost containment, which appears more and more to be a prerequisite for enacting some form of universal health insurance.

\section{B. Weighing the Arguments for Protectionist Regulation}

The protectionist tendencies of all economic regulation have appeared strongly in the administration of certificate-of-need laws. ${ }^{126}$ Among the planner-regulators articles of faith is the belief that excess capital facilities will be put o inappropriate uses for which the financing system, lacking the capacity to distinguish inappropriate utilization, will pay. Another unexamined premise is that capital investments. once made, will almost certainly be charged off to the public over time. along with

126. See Havighurst, Health Maintenance Organizations and the Health Plamers, 1978 UTAH L. REv. 123 , 140-46; see also Havighurst supra note 9 , at $1178-88$ and 1204-15. 
the attendant operating costs, through third-party payment systems dedicated to reimbursing either providers' incurred costs or insureds' incurred charges. As we have seen, however, regulation should no longer proceed on the assumption that cost-reimbursement techniques, widely employed in the past, will continue in the future. Thus, a major justification for preventing competitively induced change must be rejected.

A further justification that may be offered for protectionist policies in certification-of-need retains substantially more validity. This justification is the frequently perceived need to protect revenues that enable an existing provider to provide some service which the planner-regulators deem desirable, but which cannot support itself. Such "internal subsidization," which has been a common feature of all regulated industries, is common in hospitals, which price their services without strict regard to costs. ${ }^{127}$ This practice exposes the hospital to the threat of competition from a new provider of the overpriced services and accounts for the common claim that a new entrant is "skimming the cream" and leaving the existing hospital with the burden of providing needed but unprofitable services. Faced with such a claim, health system planner-regulators must make some difficult judgments concerning not only the short run and long run benefits of competition as an allocative mechanism, but also some other possibly important values.

It has been argued that hospitals, particularly nonprofit hospitals, employ internal subsidization to "compensat[e] for distortions and inequities in existing health insurance coverage." 128 As a general proposition, this is indisputable, but it raises many questions. If a gap exists in insurance coverage, one must inquire about the gap's origin before judging that it is one that should be filled through an internal subsidy. For example, if consumers selected insurance plans that would not pay for experimental treatments, the hospital should not be permitted to subsidize those treatments by billing more for insured services; such a subsidy would amount to a rewriting of private insurance contracts and would violate the principle of consumer choice. Moreover, it would seem much sounder for the hospital to seek explicit subsidies for its experimental work. Similarly, educational costs should be isolated by making cost differences between teaching and nonteaching institutions more visible in a competitive market. Private insurance plans, reflecting consumer choice, can serve as efficient resource allocation mechanisms only if their exclusions from, and dollar limits on, coverage are respected and not cancelled out by protected provider monopolies milking the insurance system in order to indulge preferences of their own. Competitive entry eroding the spending discretion of monopolistic hospitals would contribute greatly to the emergence of consumer preferences as the dominant force controlling the performance of the hospital sector. It would also make it necessary for those desiring public subsidies to compete for the available public funds by applying to the government.

127. Harris, Pricing Rules for Hospitals, 10 BELL J. EcoN. 224 (1979)

128. Id. at 225 . 
Probably the only internal subsidies that should be deemed to justify exclusionary regulation are those that benefit low-income patients. Despite the failure to enact a broad program of national health insurance, society has long recognized a commitment to meet the needs of patients lacking the means to purchase adequate health insurance. Hospitals have long filled a critical role in meeting this social commitment, and, in the absence of an adequate federal program, their capacity to carry on this role probably needs to be protected in some measure. By the same token, enactment of national health insurance in some form should be deemed, when it occurs, to reduce, if not to eliminate altogether, the need to foster the hospital as a monopolistic charity. But, in the short run, the health care system's planner-regulators may legitimately exclude competition as a means of preserving an existing hospital's ability to meet the vital needs of underserved and underinsured populations.

The regulatory problem here is substantial for several reasons. The existence and extent of subsidies are extremely hard to establish, particularly in the absence of uniform cost-accounting techniques. In addition, a hospital faced with competition from a certificate-of-need applicant would always threaten to close the service that the planner-regulators value most highly, even if many other services were also beneficiaries of the subsidy in jeopardy. The proper regulatory stance in such a case is to impose a heavy burden of proof on the hospital seeking protection from competition. ${ }^{129}$ Not only would its cost accounting have to be convincing and complete, but it should have to demonstrate that other, less defensible, subsidies did not exist. Because DHHS's latest certificate-of-need regulations require that a hospital obtain a "certificate of need" to close an existing service ${ }^{130}$ the hospital is no longer entirely free to choose which service it will eliminate when confronted with competition. Given that power, state regulators should not let a hospital hold a service provided to low-income patients as a hostage to get protection for its internal subsidization capability. Unless the hospital can show, with reasonable clarity, that it has no alternative candidates for closure, it should be denied the protected market position it seeks.

There are some indications that internal subsidies and the protectionism required to maintain them are not favored in the law. The 1979 health planning amendments, by exempting HMOs from certificate-of-need requirements, revealed an unwillingness to trust the regulators to evaluate a procompetitive entrant against existing providers' claims. Although the amendments expanded the statutory criteria to allow consideration of a construction project's effects "on the costs and charges to the public of providing health services by other persons," 131 this

129. Cf. Clark, Does the Nomprofit Form Fit the Hospital Industry?, 93 HARv. L. REY. 1416, 1480-84 (1980).

130. 45 Fed. Reg. 69,740, 69,746-47 (to be codified in 42 C.F.R. $\$ 123,404$ ). Serious questions can be raised, however, about whether this requirement is contemplated by or consistent with the statute Congress did not reveal an intention to extend regulatory authority to cutbacks as well as expansions of service.

131. Planning Amendments of $1979 \$ 116(\mathrm{~g})(1)$ [amending $\$ 1532(\mathrm{c})(9)(\mathrm{B})$ of the Public Health Service Act]. 
provision does not amount to a blanket acceptance of internal subsidies or an excuse for exclusionary regulation. Indeed, Congress has revealed a distinct dissatisfaction with internal subsidies in other provisions of the health planning law. Although these provisions are arguably inconsistent with the mandatory internal subsidies that DHHS has enforced against hospitals that have received Hill-Burton assistance in the past, ${ }^{132}$ those requirements may be rationalized as a way of assuring that past federal subsidies are applied as intended. In general, Congress would seem to have raised competition to a level where only a compelling need for subsidy should be deemed to outweigh it as a value.

Given the propensity of regulators to give in to protectionist temptations, DHHS regulations and state certificate-of-need laws should probably undertake to limit their discretion in this area. A potentially useful approach appears in the innovative Utah certificate-of-need law, which requires a finding that "the overriding public interest" would be affected by a subsidy's elimination as well as an estimate of the hidden cost incurred. ${ }^{133}$ This approach implies an appropriate presumption against cross-subsidies and an insistence on visibility and justification.

\section{Concilesion}

The 1979 health planning amendments restore appropriate balance to the nation's health policy by putting Congress on record for the first time in favor of relying on competition to allocate resources to and within the health care sector of the economy wherever it can serve Congressionally declared goals. The door to ultimate deregulation has thus been opened, and this article has attempted to show the path that the health system's planners and regulators are now invited to follow. Congress has revealed that its continued support for health planning and regulation does not imply that it automatically accepts the use of command-and-control methods throughout the length and breadth of the regulators' jurisdiction. Instead, Congress expects health planning and regulation to incorporate a preference for using and strengthening market mechanisms wherever that is a responsible policy. By embodying a presumption in favor of competition wherever an irredeemable market failure is not involved, health policy has now become consistent with emerging deregulation strategies in other regulated industries.

In concluding this discussion of the planner-regulators' new statutory mandate and how it might be carried out, it must be observed that we have left unexplored a vital, yet highly debatable proposition, namely, that there is a close correlation between legal mandates and regulatory performance. Realism compels recognition at this point of the possibility that it may take more than an act of Congress to change the behavior of health system planners and regulators. Even though the 1979 amendments are quite clear in embracing competition as an alternative tool for identifying and giving effect to the public interest, they necessarily leave a great deal to the planners' and regulators' judgment. Given the degree of subjectivity

132. See 42 C.F.R. $\$ 124,501-52$ (1979).

133. UTAh Code ANn. \& 26-34-11(1)(f) (1979 Supp.). 
involved in deciding whether competition and consumer choice can serve public objectives well, the new legal mandate probably cannot be enforced in a way to deprive the planner-regulators of wide discretion in deciding how much competition should be allowed and whether to anticipate and foster the emergence of more reliable market forces. Experience in other industries has frequently revealed the resourcefulness of agencies in clinging to old ways in the face of new statutory directives. ${ }^{134}$ Because health planners and regulators, as a class, are probably even more resistant than other regulators to the idea that competition and consumer choice can be constructive influences in their industry, it may seem harder to harbor high hopes that a meaningful deregulation movement has, in fact, been launched by the 1979 amendments.

Despite the difficulty of changing deep-seated values and perceptions by a statutory amendment, it is still possible to sketch a plausible scenario culminating in something similar to total deregulation of the health services industry. The essential hopeful fact is that health planning and regulation is highly decentralized, being carried out by more than $200 \mathrm{HSAs}$, by state agencies, and SHCCs in every state. Although planners and regulators are unlikely to be converted en masse to the cause of promoting competition, the possibility must be acknowledged that a significant minority of these planning and regulatory bodies will, either by design or default, give effect to the new mandate. ${ }^{135} \mathrm{By}$ tolerating and even encouraging vigorous competition and fostering financing reforms, these agencies might lay the groundwork for changes that would spread to other areas. Through the deregulation of particular services in particular markets and through nonregulatory initiatives, market-oriented health planning and innovative regulation could yield valuable regulatory experience and foster innovations in private cost containment that are transferable to other markets. Thus, the deregulation movement might benefit from persuasive natural experiments, much as airline deregulation was helped along by the superior performance of unregulated intra-state carriers in California and Texas. ${ }^{136}$

The other development lending hopefulness to the deregulation scenario is a political climate increasingly receptive to market-oriented strategies and increasingly unsupportive of traditional forms of regulation and planning. This deregulatory

134. An often cited example of an agency resisting a change in its statutory mandate was the ICC's reluctance to permit vigorous price competition between railroads and other modes of transportation, even after Congress amended the ICC's statutory authority in an apparent effort to encourage intermodal competition. See, e.g., ICC v. New York, N.H. \& H.R.R. Co., 372 U.S. 744 (1963) (overturning an ICC decision limiting intermodal price competition); Amer. Commercial Lines $v$. Louisville \& Nashville R.R., 392 U.S. 571 (1968) (upholding an ICC decision limiting intermodal price competition). For a description of the leading cases and legislative history, see Jones, ReGillated INDUSTRIEs 656-716 (2d ed. 1976). It is noteworthy, however, that the ICC's mandate to promote intermodal competition was less clear than the health planners' and regulators' new mandate to promote competition in the health care sector.

135. Utah, for example, has already indicated that it will be receptive to the new procompetitive policy adopted by Congress. In fact, Utah's Procompetitive Certificate of Need Act of 1979 predated the 1979 federal planning amendments.

136. See, e.g., Is Regulation Necessary? California Air Transportation and National Regulatory Policy, 74 Yale L. J. 1416 (1965); W. Jordan, Air Recllation iN AMerica: Effectis \& IMperficionos (1970). 
climate could easily prove decisive in the health care sector just as it has in other regulated industries. ${ }^{137}$ Like the Civil Aeronautics Board, which under Alfred Kahn's chairmanship took the lead in deregulating the airlines, health system planner-regulators may sense that the wind is blowing strongly in the direction of the market strategy and may chart their course so that the wind is at their backs, not in their faces. Indeed, recent cuts in HSA budgets ${ }^{138}$ may presage an antiplanning gale that will induce the agencies to abandon their foundering command-and-control flagship for a new, more seaworthy vessel-the Competition Bandwagon.

The key question, then, is not so much what the 1979 health planning amendments say as whether they signify that a definitive political choice has been, or is in the process of being, made. The thesis here is that Congress has been uncharacteristically forthright and definitive in stating its preference in the new amendments. Morever, its choice seems likely to stick, both because it is technically sound and because it enjoys political support as a promising middle ground between heavy-handed regulation and the unsatisfactory status quo. If this assessment is accurate, many planners and state regulators can be expected to accept Congress' procompetitive choice. Not only may their own political future depend, ironically, upon their accepting the deregulatory mission, but many of them may learn to view introducing competition as both a worthy challenge and a promising strategy for achieving substantive reforms. And, indeed, the competition strategy does seem a better way to bring about needed change than the perpetual political infighting and regulatory naysaying that have hitherto characterized health planning and certification-of-need.

137. See. e.g., Sarasohn, Trucking Deregulation Plans Progress, 38 Conc. Q. Weekly ReP. 581 (1980) (suggesting that President Carter's support for trucking deregulation would have resulted in substantial deregulation by administrative decision even if Congress had not passed a deregulation bill); Sarasohn, FCC Acts to Deregulate Telecommunications, 38 Cong. Q. WeEkLY RE.P. 933 (1980) (describing FCC steps to deregulate telecommunications); Kelleher, Deregulation and the Practicing Attorney, 44 J. AIR L. \& Com. 261, 280-81 (1978) (describing CAB steps to deregulate air fares prior to the 1978 deregulation act but after deregulation had gained political credibility).

138. The federal appropriation for HSAs was 20 percent lower in fiscal year 1981 than it was in fiscal year 1980. Rorrie Tells Planners to Limit Their Objectives, Health Planning \& Manpower Report 5 (Jan. 14, 1981). 